\title{
Geosynthetic-reinforced pile-supported embankments: state of the art
}

\author{
S. J. M. van Eekelen ${ }^{1}$ and J. $\operatorname{Han}^{2}$ \\ ${ }^{1}$ Geotechnical researcher and adviser at Deltares, Geo-engineering Department, Delft, Netherlands, \\ E-mail: suzannevaneekelen@deltares.nl (corresponding author) \\ ${ }^{2}$ Professor at Civil, Environmental and Architectural Engineering (CEAE) Department, The University \\ of Kansas, Lawrence, KS, USA, E-mail: jiehan@ku.edu
}

Received 09 June 2019, revised 02 January 2020, accepted 03 January 2020, published 07 April 2020

\begin{abstract}
Geosynthetic-reinforced pile-supported embankments have been increasingly used worldwide to support earth structures. A significant amount of research has been conducted by many researchers and engineers in recent years. This paper provides a state-of-the-art review of this technology, and of important developments and results obtained throughout the years that help to better understand the mechanisms that play an important role in the design, construction, and performance of these systems. This paper begins with terminologies and historical developments. It then focuses on load transfer mechanisms and practical design and proposes topics for future research. The supplemental material gives tips for construction details and instrumentation for performance evaluation.
\end{abstract}

KEYWORDS: Geosynthetics, Reinforcement, Piled embankments, Load transfer platforms, Soil arching, Deformation, Construction, Design, Instrumentation

REFERENCE: van Eekelen, S. J. M. and Han, J. (2020). Geosynthetic-reinforced pile-supported embankments: state of the art. Geosynthetics International, 112-141. [https://doi.org/10.1680/ jgein.20.00005]

\section{INTRODUCTION}

The construction of geotechnical infrastructure often encounters weak and soft soils with low strength and high compressibility. Possible bearing failure, excessive settlement and slope instability are the geotechnical engineering concerns and/or risks affecting infrastructure constructed on these soils. Time and cost must also be considered in the design. Geosynthetic-reinforced pilesupported embankments have become an effective and often economical solution for overcoming these concerns and/or risks when they are used to support highways, railways, storage tanks, industrial areas, and even buildings. A significant amount of research has been conducted by many researchers and engineers in the past three decades to advance this technology by better understanding its mechanisms and improving its design, construction, and instrumentation.

The First International Workshop on GeosyntheticReinforced Pile-Supported Embankments was organized at Tongji University, Shanghai, China on 14-16 June 2017 with the following objectives: (1) to understand current practices and research in different countries, (2) to seek consensus or identify differences in common issues, (3) to identify topics for future research, and (4) to explore opportunities for future collaboration. Following the workshop, this special issue on this topic was prepared to include some of the work presented at the workshop, the invited papers contributed by a few experts, and the papers received by the journal. This paper provides a state-of-the-art review of the technology based on the authors' personal work, research results from others in the literature, and some outcomes from the workshop and this special issue.

\subsection{Terminologies and definitions for pile-supported embankments}

Different terminologies have been used by researchers and engineers for this technology. They include but are not limited to: geosynthetic-reinforced pile-supported embankments, basal reinforced piled embankments, geosynthetic-reinforced piled embankments, geosynthetic-reinforced column-supported embankments, and rigid inclusion ground improvement. The term 'geosynthetic-reinforced pile-supported embankments' is used in this paper. Geosynthetic-reinforced pile-supported (GRPS) embankments were developed in an advance from conventional pile-supported (CPS) embankments with no geosynthetic reinforcement above the piles. Figure 1 shows both embankment systems. CPS 


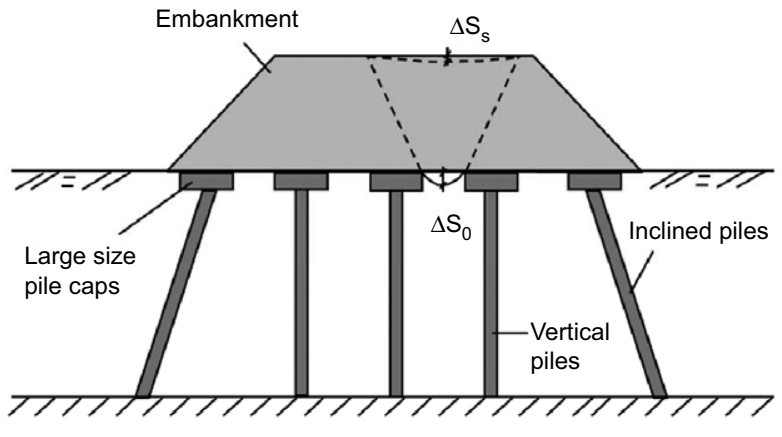

Firm soil or bedrock

(a)

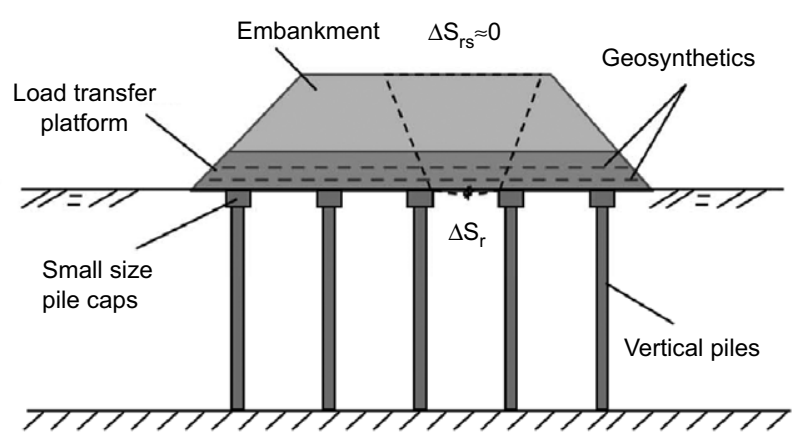

Firm soil or bedrock

(b)

Figure 1. (a) Conventional and (b) geosynthetic-reinforced pile-supported embankments (Han and Gabr 2002)

embankments often include inclined piles at the edges to resist the lateral thrust from the embankment and large pile caps to reduce the span between piles. GRPS embankments include one or multiple layers of geosynthetic reinforcement to resist the lateral thrust from the embankment, and a load transfer platform formed by the geosynthetic reinforcement and granular fill to bridge over the piles with smaller pile caps. A theoretical comparison between a CPS and a GRPS embankment is provided in Section 2.1. When larger diameter columns (such as deep mixed columns and jet-grouted columns) are used, caps are not necessary. In these cases, column heads are described as 'pile caps' in this paper. Large pile caps or the load transfer platform are used to reduce differential settlement at the base of the embankment, which may be reflected to the surface of the embankment. Most projects use end-bearing piles; however, some projects use floating piles.

\subsection{Historical development}

The concept of a pile-supported embankment can be traced back many years. One of the examples is a bathhouse built in Masada in Israel between 37 and 31 BCE (before the common era). This bathhouse (see Figure 2) had a mosaic or tiled floor built on a platform supported by columns with caps. Hot steam passed through the space between the columns to heat up the bathhouse. In this system, the load transfer platform is a slab, which is different from a fill platform in terms of materials and mechanisms but has a similar function. Except for this difference, all the components of the current pile-supported embankment system are included in this floor structure.

An early application of pile-supported embankments in Holland dates back to the 1930s. To construct a road over peat, the engineer Keverling Buisman first considered using a fascine mattress to stabilize the road given the results of six cone penetration tests (CPTs). After conducting more CPTs, he had second thoughts and wrote: 'To prevent complaints and unfavorable comments ... a piled road would be more 'appreciated". (Keverling Buisman 1937). It is interesting to note that public opinion was an important, or even the prime, consideration for Keverling Buisman. The road with

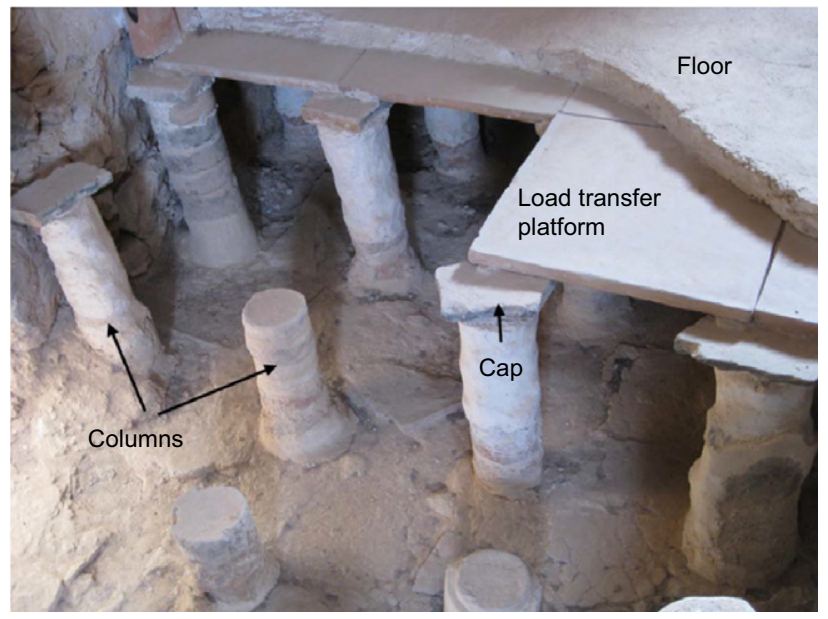

Figure 2. Column-supported floor in Masada, Israel (photo taken by J. Han)

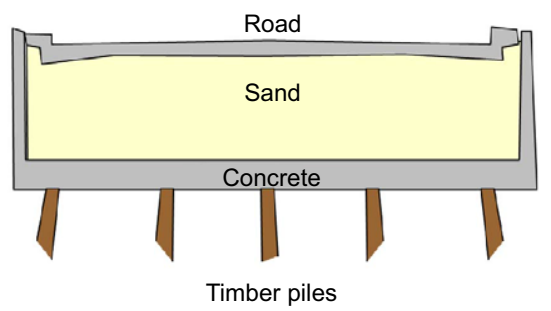

Figure 3. Early application of pile-supported embankment (modified after Keverling Buisman 1937)

the cross-section shown in Figure 3 was designed and constructed with a concrete slab on timber piles, which were installed upside down to generate sufficient bearing capacity.

Rathmayer (1975) proposed design guidelines for the percentage coverage of pile caps in CPS embankments based on the height of the embankment and the quality of the embankment fill. The coverage of pile caps ranged from $30 \%$ to more than $70 \%$. A high embankment with crushed stone fill requires a lower percentage coverage than a low embankment with gravel fill.

Holtz and Massarsch (1976) reported the first use of geosynthetic reinforcement in pile-supported 
embankments in Sweden in 1975. Reid and Buchanan (1984) reported an early application of a geosynthetic-reinforced pile-supported embankment in the UK for an approach to a bridge in Scotland. The first application of a geosynthetic-reinforced pilesupported embankment in the United States (ASCE 1997) was in 1994 for storage tanks at the Westway Terminal in Philadelphia, PA, where vibro-concrete columns were used.

On the basis of model tests on conventional pilesupported embankments without geosynthetic reinforcement, Hewlett and Randolph (1988) proposed a semicircular dome soil arching model to estimate the load carried by piles. The British Standards Institution developed a design code for applications of reinforcement techniques to soils, i.e., BS8006 (BSI 1995) which included the design of geosynthetic-reinforced pile-supported embankments. This code was updated in 2010 as BS8006-1 (BSI 2010). Several other codes or manuals have been developed in different countries, including EBGEO (2010) in Germany, (Van Eekelen and Brugman 2016) in the Netherlands, and the FHWA Ground Modification Methods - Reference Manual (Schaefer et al. 2017) in the United States.

\section{LOAD DISTRIBUTION}

\subsection{What is soil arching?}

Soil arching is a common phenomenon found in many earth structures in geotechnical engineering applications such as buried pipes and culverts, tunnels and pilesupported embankments. Soil arching occurs when differential movement develops between structural elements (such as piles) and soils. In pile-supported embankments, the area between the piles under the embankment deforms more than the piles. This differential deformation induces soil arching in the embankment fill by transferring more load to the piles and less load to the area between the piles. Soil arching occurs both in CPS and in GRPS embankments but the relatively small pressures on the area between the piles are distributed differently in these two embankments.

In a CPS embankment, the subsoil between the piles settles approximately uniformly even though the soil close to the pile may deform slightly less due to the pile skin friction. This results in a more or less uniformly distributed pressure on the subsoil between the piles.

However, in a GRPS embankment, the load that rests on the area between the pile caps (in other words, on the reinforcement that deforms with the underlying subsoil) is not distributed uniformly but as follows.

- A relatively large part of the load is exerted on the reinforcement strips between adjacent piles because these strips have the shortest span between adjacent piles, resulting in the reinforcement strips deflecting less than elsewhere, and attracting a relatively higher load.

- The load on a reinforcement strip is not distributed uniformly: more load is exerted at the location closer to the pile cap as a result of the reinforcement deflecting less at this location than in the middle between pile caps.

This interaction results in a load distribution of the kind shown in Figure 4: the load is concentrated on the reinforcement strips, with highest pressure close to the piles, and lowest pressure in the center. Figure 4a shows the load distribution resulting from arching: less reinforcement deformation attracts more load. When there is sufficient differential settlement between subsoil and piles, most load therefore goes to the pile caps (load part $A$ due to arching, in red, in $\mathrm{kN} /$ pile) and a relatively large part of the remaining load goes to the reinforcement strips between adjacent pile caps, where it is distributed approximately as an inverse triangle.

The load distribution in Figure 4a has been confirmed by measurements reported by Zaeske (2001), Sloan (2011), and Van Eekelen et al. (2011b 2012a, 2012b), and by numerical calculations by Han and Gabr (2002),

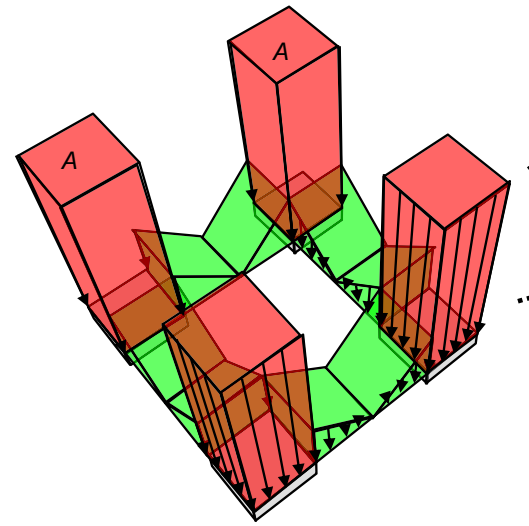

(a)

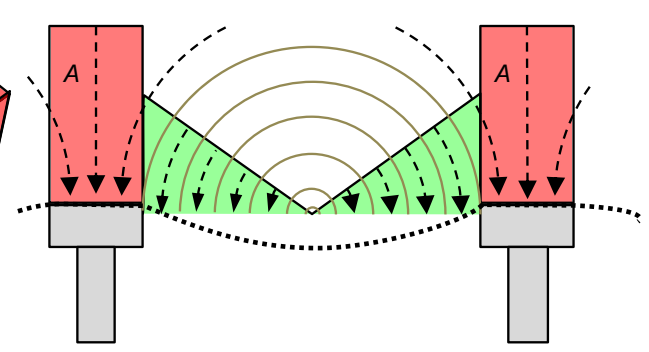

(b)

Figure 4. Arching in a GRPS embankment: (a) approximation of the load distribution resulting from arching and (b) concentric arches explaining the load distribution 
Wachman et al. (2010), Han et al. (2012), Van der Peet and Van Eekelen (2014), Girout et al. (2014), Lehn et al. (2016), Yu et al. (2016), and Zhuang et al. (2020).

Figure $4 \mathrm{~b}$ shows how concentric arches can be used to explain the load distribution in Figure 4a. In this model, the load is transferred along the arches. Larger arches transfer more load. This concept was further refined in the Concentric Arches model (Van Eekelen 2015) shown in Figure 5 . This model has been confirmed by numerical work - for example by Lehn et al. (2016) and Van der Peet and Van Eekelen (2014) - and two-dimensional (2D) tests, for example by Rui et al. (2019a) (see Figure 8, later in the paper). It has been used by King et al. (2017b) for the ultimate limit state (ULS) design.

Soil arching is influenced by many factors, including geometry (embankment height, pile cap size, pile spacing, and pile pattern), fill quality, differential settlement and therefore subsoil consolidation, geosynthetic and surcharge load. These factors are discussed in Section 2.5.

\subsection{Terminologies and definitions for load distribution}

Different terminologies and definitions have been used in the literature to describe or define load distribution, including soil arching. This paper uses the following terminologies to describe the vertical loads in the CPS and GRPS embankments due to fill self-weight and surcharge load (see Figure 6). Part of the total load (referred to as load part $A$, in $\mathrm{kN} /$ pile) is transferred to the piles directly. As explained earlier, this part is relatively large because of soil arching. The second, residual load part (referred to as $B+C$, in $\mathrm{kN} / \mathrm{pile}$ ) rests on the reinforcement and the underlying subsoil. This residual load part is divided further into load part $B$, which is transferred to the piles through the reinforcement, and load part $C$, which rests on the subsoil underneath the reinforcement (in other words, the subsoil support). In CPS embankments, $B=0 \mathrm{kN}$. Some researchers attribute $A$ to arching, and $B$ to the 'tensioned membrane effect' (an example being Pham 2020). The total of $A, B$ and $C$ is the total load in $\mathrm{kN}$ in a unit cell area including a pile: $A+B+C=$ $(\gamma H+p) \cdot A_{\mathrm{i}}=W_{\text {tot }}$, where $A_{\mathrm{i}}$ is the pile unit coverage area (i.e. $s_{x} \cdot s_{y}$ in a rectangular pile pattern, where $s_{x}$ and $s_{y}$ are the center-to-center pile spacing parallel to the $x$ - and $y$-axes respectively).

Researchers have used different terminologies to describe the level of arching. For example, they have used either the load part $A$ versus the residual load $B+C$ (arching; listed in Table 1), or the total pile load $A+B$ versus the subsoil support $\mathrm{C}$ (arching + membrane effect; listed in Table 2). In these tables, $\gamma$ is the fill unit weight $\left(\mathrm{kN} / \mathrm{m}^{3}\right), p(\mathrm{kPa})$ is the surcharge pressure, $A_{\mathrm{p}}$ is a pile cap area, $A_{\mathrm{g}}$ is the area of the geosynthetic between the pile caps: $A_{\mathrm{g}}=\left(s_{x} \cdot s_{y}-A_{\mathrm{p}}\right)$ for a rectangular pile pattern, and the geosynthetic strip cross-sectional area

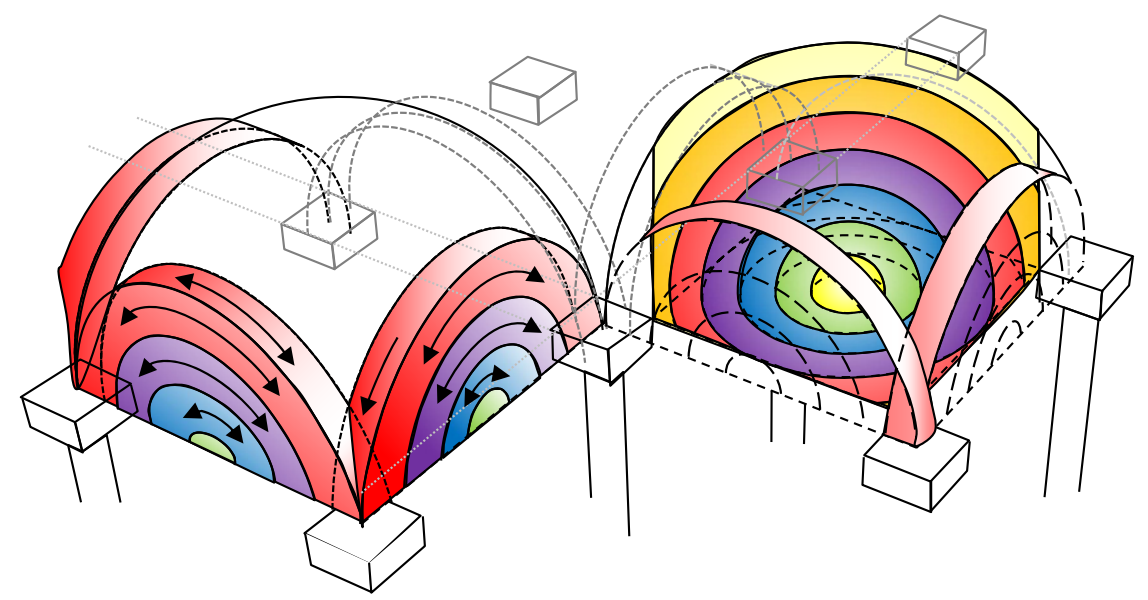

Figure 5. Three-dimensional version of the Concentric Arches (CA) model (Van Eekelen et al., 2013)

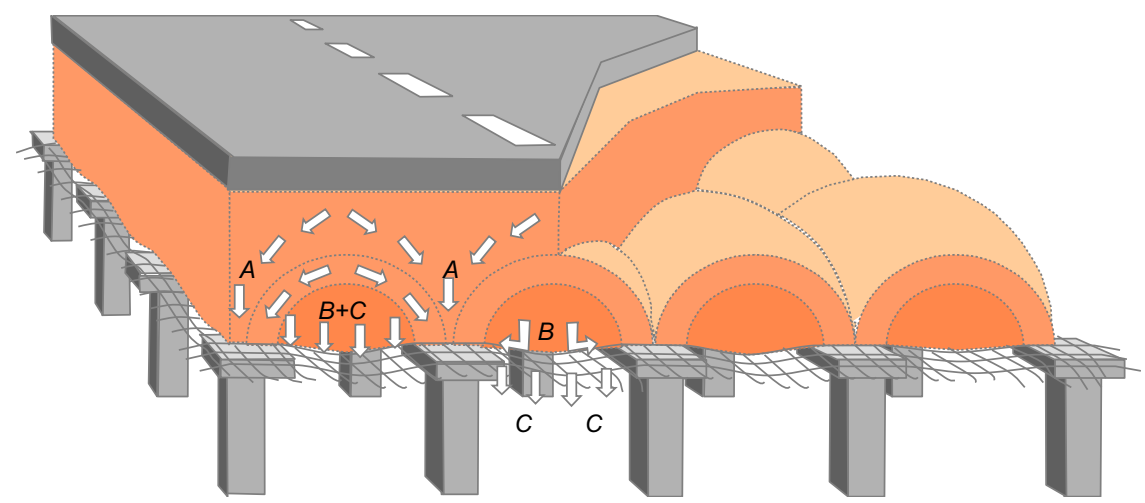

Figure 6. Definitions of load distribution in a GRPS embankment (after Van Eekelen 2015)

Geosynthetics International, 2020, 27, No. 2 


\begin{tabular}{|c|c|c|c|c|c|}
\hline Terminology & Symbol & Unit & $\begin{array}{l}\text { Pile-supported embankment } \\
\text { with geosynthetic } \\
\text { reinforcement }\end{array}$ & $\begin{array}{l}\text { Pile-supported embankment } \\
\text { without geosynthetic } \\
\text { reinforcement }(B=0)\end{array}$ & Source \\
\hline \multicolumn{6}{|l|}{ (1) Arching $A$} \\
\hline Arching $A$, see Figure 6 & $A$ & $\mathrm{kN} /$ pile & $A=W_{\mathrm{tot}}-(B+C)$ & $A=W_{\mathrm{tot}}-C$ & $\begin{array}{l}\text { Van Eekelen and Bezuijen (2008), } \\
\text { Van Eekelen and Brugman (2016) }\end{array}$ \\
\hline Arching $A \%$ & $A \%$ & $\mathrm{kN} / \mathrm{kN}$ & $A \%=A /(A+B+C)=A / W_{\mathrm{tot}}$ & $A \%=A /(A+C)=A / W_{\mathrm{tot}}$ & $\begin{array}{l}\text { Van Eekelen and Bezuijen (2008), } \\
\text { Van Eekelen and Brugman (2016) }\end{array}$ \\
\hline Pile efficacy ${ }^{c}$ & $E(=A \%)$ & $\mathrm{kN} / \mathrm{kN}$ & $A / W_{\text {tot }}$ where $p=0 \mathrm{kPa}$ & $A / W_{\text {tot }}$ where $p=0 \mathrm{kPa}$ & Hewlett and Randolph (1988) ${ }^{\mathrm{a}}$ \\
\hline Load distribution factor $=A \%$ & $E_{\mathrm{L}}(=A \%)$ & $\mathrm{kN} / \mathrm{kN}$ & $A / W_{\text {tot }}$ & - & EBGEO (2010) \\
\hline \multicolumn{6}{|c|}{ (2) Total load on geosynthetic between the pile caps $B+C$} \\
\hline Residual load $B+C$, see Figure 6 & $B+C$ & $\mathrm{kN} /$ pile & $B+C$ & $C$ & $\begin{array}{l}\text { Van Eekelen and Bezuijen (2008), } \\
\text { Van Eekelen and Brugman (2016) }\end{array}$ \\
\hline Residual load $(B+C) \%$, see Figure 6 & $(B+C) \%$ & $\mathrm{kN} / \mathrm{kN}$ & $\begin{array}{c}(B+C) \%=(B+C) / W_{\mathrm{tot}}= \\
\quad(B+C) /(A+B+C)\end{array}$ & $C \%=C / W_{\mathrm{tot}}=C /(A+C)$ & $\begin{array}{l}\text { Van Eekelen and Bezuijen (2008), } \\
\text { Van Eekelen and Brugman (2016) }\end{array}$ \\
\hline $\begin{array}{l}\text { Distributed load on geosynthetic strip between } \\
\text { adjacent piles }\end{array}$ & $W_{\mathrm{T}}$ & $\mathrm{kN} / \mathrm{m}$ & $B / A_{\text {strip }}$ & - & $\mathrm{BS} 8006^{\mathrm{b}}$ \\
\hline Normalized ratio of stress & $p / p_{0}$ & $\mathrm{kPa} / \mathrm{kPa}$ & - & $\begin{array}{l}\sigma_{\mathrm{s}} /(\gamma H)=\left(C / A_{\mathrm{g}}\right) /\left((A+B+C) / A_{\mathrm{i}}\right) \\
\quad \text { where } p=0 \mathrm{kPa}\end{array}$ & Iglesia et al. $(1999)^{\mathrm{d}}$ \\
\hline Stress reduction ratio/soil arching ratio & SRR or $\rho$ & $\mathrm{kPa} / \mathrm{kPa}$ & $\begin{array}{l}\sigma_{\mathrm{g}} /(\gamma H+p)=\left((B+C) / A_{\mathrm{g}}\right) / \\
\quad\left((A+B+C) / A_{\mathrm{i}}\right)\end{array}$ & $\sigma_{\mathrm{s}} /(\gamma H+p)=\left(C / A_{\mathrm{g}}\right) /\left((A+B+C) / A_{\mathrm{i}}\right)$ & $\begin{array}{l}\text { Han and Gabr (2002), King et al. (2017b), Han et al. } \\
\text { (2019) }\end{array}$ \\
\hline
\end{tabular}

${ }^{\text {a } H e w l e t t ~ a n d ~ R a n d o l p h ~(1988) ~ a s s u m e d ~ t h a t ~ t h e ~ s u r c h a r g e ~ l o a d ~} p=0 \mathrm{kPa}$

${ }^{\mathrm{b} I n}$ BS8006 (BSI 2010), subsoil support $C$ is $0 \mathrm{kN}$ and the full pile load B in $\mathrm{kN}$ is exerted on each of the two reinforcement strips as a conservative assumption, as explained by Van Eekelen $e$ al. (2011a)

${ }^{\mathrm{C}}$ Note that Tables 1 and 2 contain different definitions of the efficacy or efficiency $E$.

${ }^{\mathrm{d}}$ Low et al. (1994) and Iglesia et al. (1999) assumed that the surcharge load $p=0 \mathrm{kPa}$.

Table 2. Terminologies and definitions for the arching + membrane effect in a pile-supported embankment

\begin{tabular}{|c|c|c|c|c|c|}
\hline Description & Symbol & Unit & $\begin{array}{l}\text { Pile-supported } \\
\text { embankment } \\
\text { with geosynthetic } \\
\text { reinforcement }\end{array}$ & $\begin{array}{l}\text { Pile-supported } \\
\text { embankment } \\
\text { without geosynthetic } \\
\text { reinforcement }(B=0)\end{array}$ & Source \\
\hline \multicolumn{6}{|l|}{ (1) Arching + membrane effect $(A+B)$} \\
\hline Arching + membrane effect $(A+B) \%$ & $(A+B) \%$ & $\mathrm{kN} / \mathrm{kN}$ & $(A+B) \%=(A+B) / W_{\text {tot }}$ & $A \%=A / W_{\mathrm{tot}}$ & This paper \\
\hline Pile efficacy ${ }^{\mathrm{a}}$ (or pile efficiency) & & $\mathrm{kN} / \mathrm{kN}$ & $(A+B) /\left(\gamma H A_{\mathrm{i}}\right)$ & $A /\left(\gamma H A_{\mathrm{i}}\right)$ & Low et al. $(1994)^{\mathrm{b}}$ \\
\hline $\begin{array}{l}\text { Stress concentration ratio or } \\
\text { pile-subsoil stress ratio }\end{array}$ & $N$ & $\mathrm{kPa} / \mathrm{kPa}$ & $\left((A+B) / A_{\mathrm{p}}\right) /\left(C / A_{\mathrm{g}}\right)$ & $\left(A / A_{\mathrm{p}}\right) /\left(C / A_{\mathrm{g}}\right)$ & $\begin{array}{l}\text { Han and Gabr (2002), } \\
\text { Liu et al. (2007) }\end{array}$ \\
\hline \multicolumn{6}{|l|}{ (2) Subsoil support $C$} \\
\hline Stress reduction ratio & SRR & $\mathrm{kN} / \mathrm{kN}$ & $C l\left(\gamma H A_{\mathrm{g}}\right)$ & $C /\left(\gamma H A_{\mathrm{g}}\right)$ & Low et al. (1994) ${ }^{\mathrm{b}}$ \\
\hline Soil arching ratio & $\rho$ & $\mathrm{kPa} / \mathrm{kPa}$ & & $\sigma_{\mathrm{s}} /(\gamma H+p)$ & $\begin{array}{l}\text { McNulty (1965), } \\
\text { Han and Gabr (2002) }\end{array}$ \\
\hline
\end{tabular}

${ }^{\mathrm{a}}$ Note that Tables 1 and 2 contain different definitions of the efficacy or efficiency $E$.

${ }^{\mathrm{b}}$ Low et al. (1994) and Iglesia et al. (1999) assumed that the surcharge load $p=0 \mathrm{kPa}$. 
$A_{\text {strip }}=a_{(e q)} \cdot\left(s_{x ; y}-a_{(e q)}\right)$ for a rectangular pile pattern and a square pile cap with a width $a$, or a circular pile cap with an equivalent width $a_{e q}, \sigma_{\mathrm{s}}(\mathrm{kPa})$ is the pressure on the subsoil $\left(=C / A_{\mathrm{g}}\right), \quad \sigma_{\mathrm{g}}(\mathrm{kPa})$ is the pressure on the reinforcement between the pile caps: $\sigma_{\mathrm{g}}=(B+C) / A_{\mathrm{g}}$ and $p_{0}(\mathrm{kPa})$ is the average pressure on the level of the pile caps and the reinforcement; $\sigma_{0}=p_{0}=(A+B+C) / A_{\mathrm{i}}=$ $\gamma H+p$.

\subsection{Progressive development of arching}

Arching development depends on embankment fill height and properties, pile cap size and pile cap spacing, displacement, and the presence of geosynthetic reinforcement. This development has been investigated by trapdoor or trapdoor-like tests. Iglesia (1991) and Iglesia et al. $(1999,2014)$ proposed the concept of a ground reaction curve (GRC) to describe the development of soil arching with trapdoor displacement from initial arching through maximum arching and stress recovery to ultimate arching, by changing the shape and height of slip surfaces from circular, tall elliptical or triangular to ultimately vertical slip surfaces. They developed this concept on the basis of centrifuge tests without reinforcement. This concept will be further discussed in Section 3.3. Wu et al. (2019) theoretically modeled a similar evolution of the loosening zone (in other words, soil arching) above a tunnel in sand in three stages with three different arch shapes and heights as shown in Figure 7. The stages in Wu et al. (2019) are similar to those proposed by Han et al. (2017). When an embankment is high enough to develop a plane of equal settlement, full arching can be mobilized. However, when the embankment is not high enough to have a

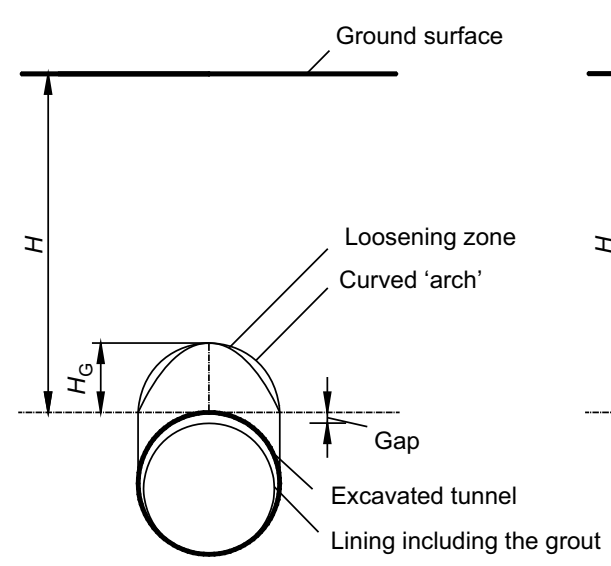

(a)

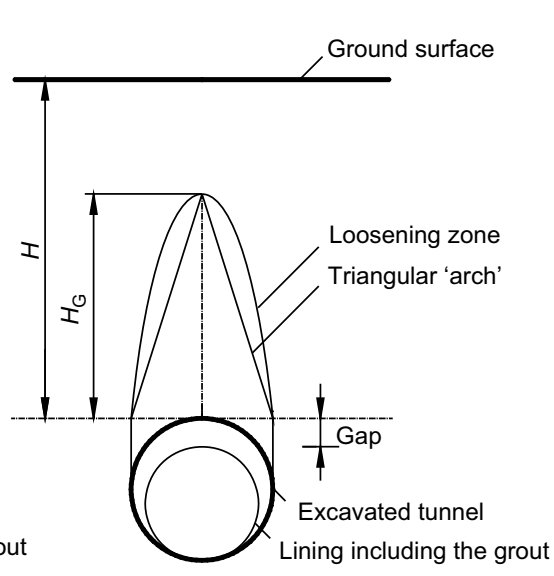

(b)

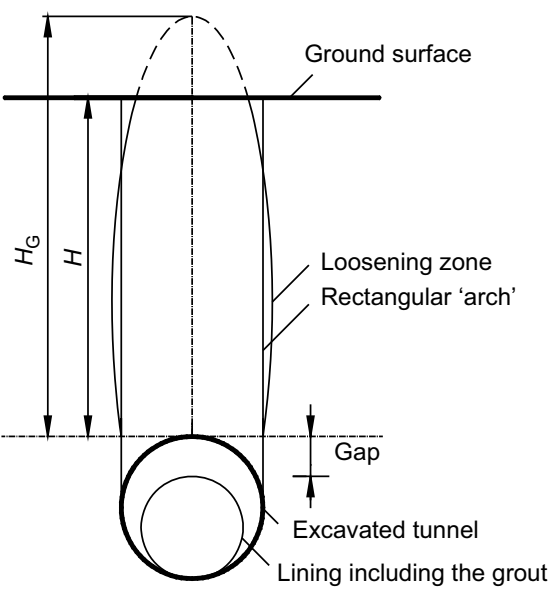

(c)

Figure 7. Evolution of loosening zone above tunnel in sand: (a) curved 'arch' when ground loss ratio is less than 4.0\%; (b) triangular 'arch' when ground loss ratio is within the range of $4.0-10.0 \%$; (c) rectangular 'arch' when ground loss ratio is more than $10.0 \%(W u$ et al. 2019)

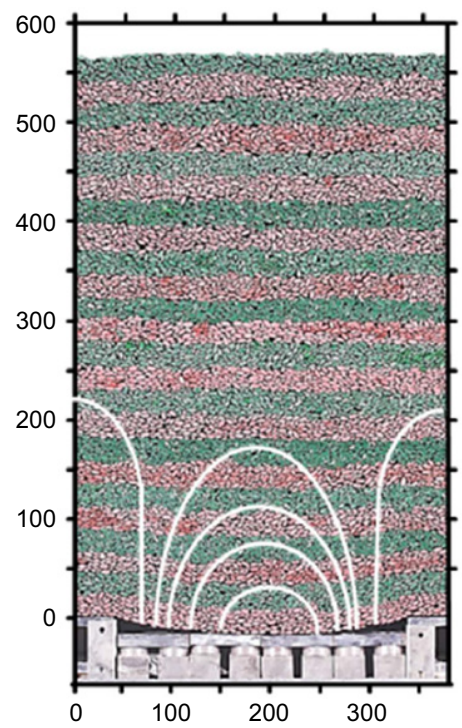

(a)

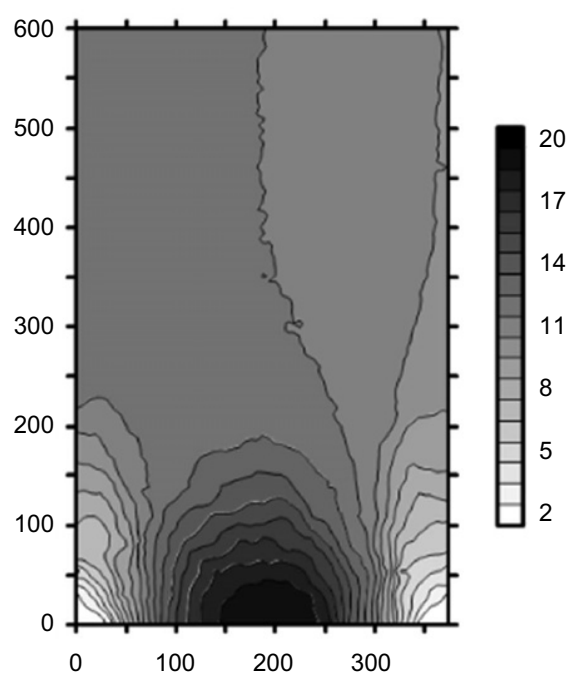

(b)

Figure 8. Dimensions and Deformations ( $\mathrm{mm})$ in the 2D reinforced tests of Rui et al. (2019a): the deformations show concentric arches (the highest arches are higher than circles; the lowest arches are lower than circles): (a) photo of deformed analogical soil; (b) deformation contours 
plane of equal settlement, only partial arching can be mobilized.

If a type of reinforcement with sufficient stiffness is used, the ultimate soil arching, with vertical slip surfaces, is generally not reached because the limited reinforcement deflection minimizes the displacement of the embankment fill. Rui et al. (2016a 2019a) compared the progressive development of arching using multiple-trapdoor tests with and without reinforcement. Without reinforcement, they found that arching developed in a way similar to that observed by Iglesia $e t$ al. (1999) and Wu et al. (2019). When Rui et al. (2019a) used geosynthetic reinforcement in their tests, they found that arching developed differently and that there

Table 3. Different arching states in analytical models for CPS and GRPS embankments with different embankment heights. The dashed arrows indicate the directions of the largest principal stresses

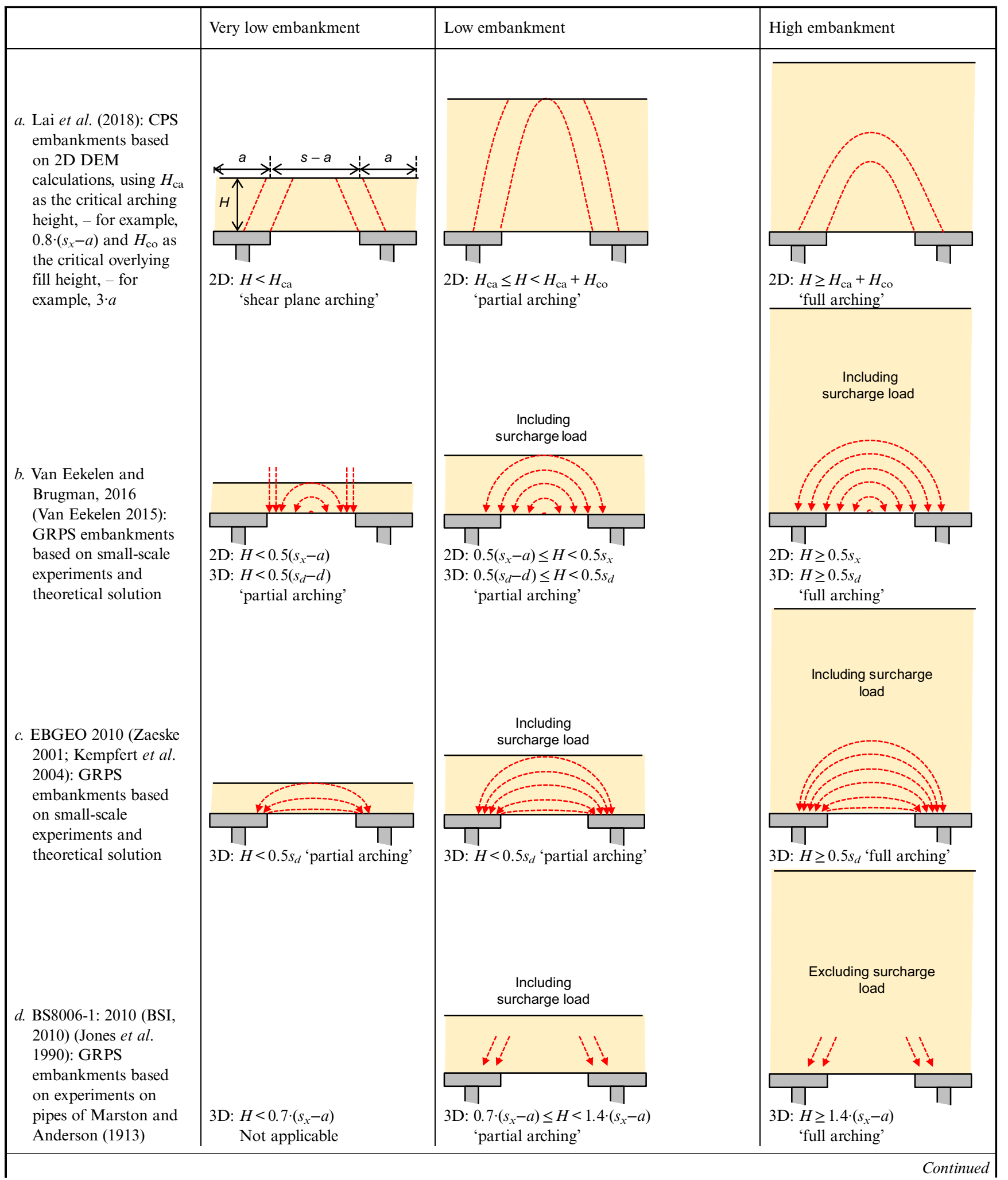

Geosynthetics International, 2020, 27, No. 2 
Table 3. Continued

e. Rui et al. (2019a): GRPS embankments

based on 2D experiments

f. Hewlett and Randolph (1988): based on laboratory model test data and theoretical solution. CPS embankments, although Hewlett and Randolph (1988) recommended the inclusion of GR without taking the influence of the GR into account or giving calculation rules for the GR design.

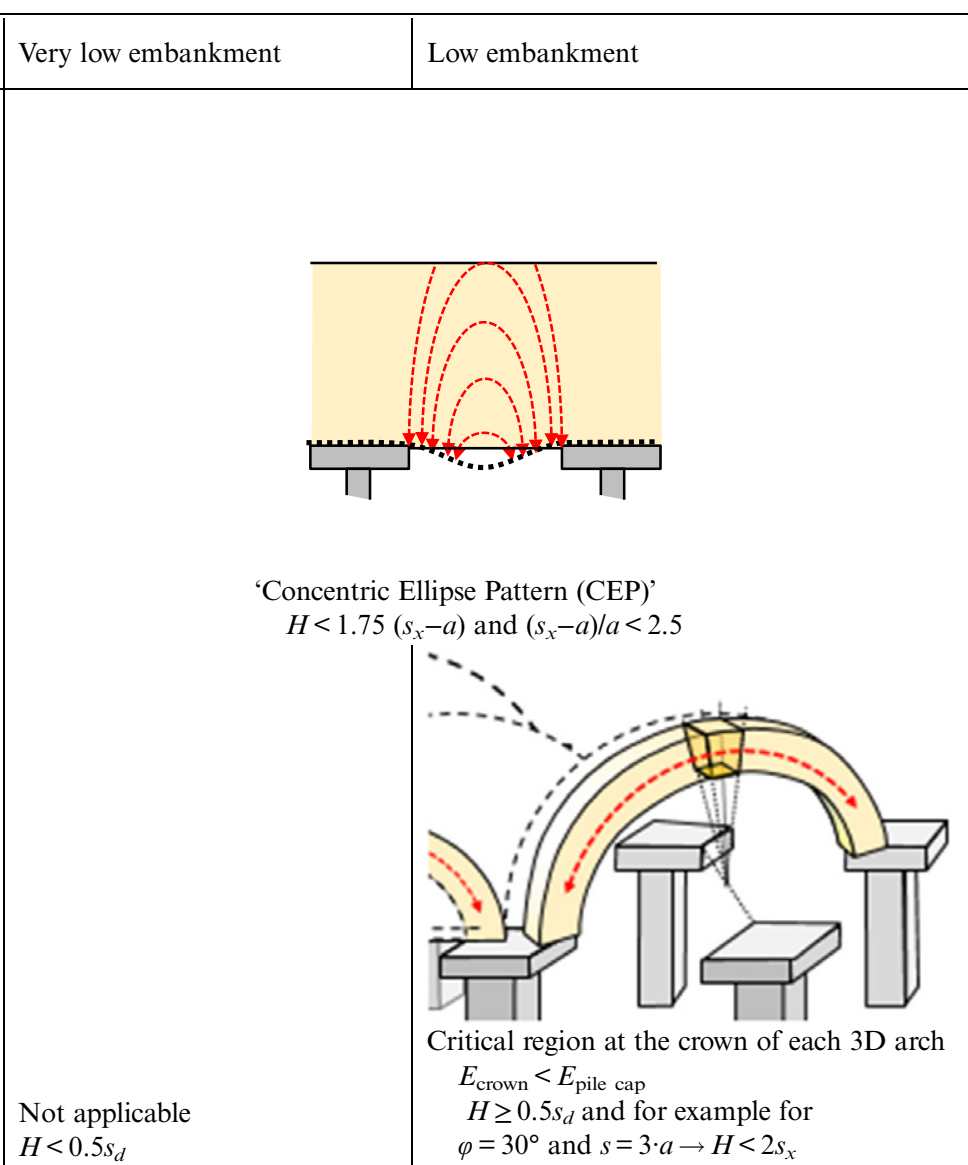

High embankment

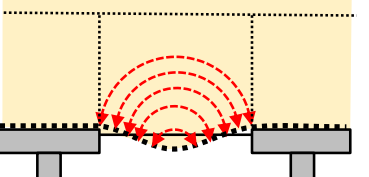

'Equal Settlement Pattern Concentric Arches (ESP-CA) $H \geq 1.75\left(s_{x}-a\right)$ and $\left(s_{x}-a\right) / a \geq 2.5$

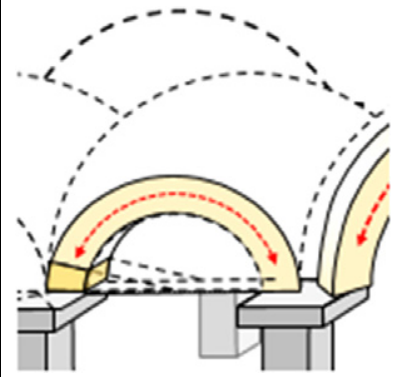

Critical region at the pile caps: $E_{\text {pile cap }}<E_{\text {crown }}$, which occurs for example for $\varphi=30^{\circ}$ $s=3 \cdot a \rightarrow H>2 s_{x}$

Note: GR = geosynthetic reinforcement.

Table 4. Design requirements or recommendations for minimum embankment height

\begin{tabular}{|c|c|c|}
\hline & Minimum embankment height & \\
\hline \multicolumn{3}{|l|}{ Standards and design guidelines } \\
\hline $\begin{array}{l}\text { British Standard BS8006-1: } 2010 \text { (BSI, } \\
\text { 2010) }\end{array}$ & $0.7\left(s_{x}-a\right)$ & \\
\hline $\begin{array}{l}\text { Dutch Design Guideline Van Eekelen } \\
\text { and Brugman (2016) }\end{array}$ & $0.66\left(s_{d}-a\right)$ & \\
\hline FHWA (Schaefer et al. 2017) & $\operatorname{Max}\left[1.5\left(s_{x}-a\right), 1.15 s^{\prime}+1.44 d\right]$ & Critical height based on laboratory model tests and field test data \\
\hline \multirow[t]{3}{*}{ German Standard EBGEO (2010) } & $0.8\left(s_{d}-a\right)$ & For static loads \\
\hline & $1.0\left(s_{d}-a\right)$ & For variable loads; negative influence of variable load \\
\hline & $2.0\left(s_{d}-a\right)$ & $\begin{array}{l}\text { For variable loads; negative influence of variable load is } \\
\text { negligible }\end{array}$ \\
\hline $\begin{array}{l}\text { Nordic Guidelines for Reinforced Soils } \\
\text { and Fills (NGG 2004) }\end{array}$ & $1.2\left(s_{x}-a\right)$ & \\
\hline \multicolumn{3}{|l|}{ Previous research recommendations } \\
\hline Terzaghi (1943) & $2.0\left(s_{x}-a\right)$ & \\
\hline Carlsson (1987) & $1.87\left(s_{x}-a\right)$ & \\
\hline Han and Gabr (2002) & $1.3\left(s_{x}-a\right)$ & Critical height based on numerical results \\
\hline Chen et al. (2008b) & (1.4 to 1.6$)\left(s_{x}-a\right)$ & Critical height based on laboratory model test data \\
\hline Chen et al. (2010) & (1.1 to 1.5$)\left(s_{x}-a\right)$ & Critical height based on field test data \\
\hline McGuire (2011) and Filz et al. (2012) & 3D: $H \geq 1.15 \cdot s^{\prime}+1.44 d$ & Critical height based on laboratory model tests and field test data \\
\hline
\end{tabular}

Note: $a=$ pile cap width; $d=$ pile cap diameter; $s_{x}=$ center-to-center spacing between piles in the $x$-direction; $s_{d}=$ center-to-center spacing between piles in the diagonal direction and $s^{\prime}=0.5 \cdot\left(s_{d}-d\right)$.

were no triangular or vertical slip planes. They observed only a concentric ellipse deformation pattern as shown in Figure 8 .
If the geosynthetic reinforcement is designed properly, resulting in a limited maximum reinforcement deflection, different arching states may exist for different 
embankment heights. Several researchers have proposed different models and used different approaches to describe these states for higher and lower embankments. They are listed in Table 3. For example, Lai et al. (2018) distinguished between three types of arching in CPS embankments on the basis of 2D discrete element method (DEM) analyses: (a) shear plane arching, (b) partial arching, and (c) full arching separated by two critical heights. These two critical heights are: (1) the critical arching height $H_{\mathrm{ca}}$ (e.g. $0.8\left(s_{x}-a\right)$ ) and (2) the critical overlying filling height $H_{\text {co }}$ (e.g. 3.0a). Several other researchers have made similar distinctions but used the different assumptions and terminologies shown in Table 3. The following parameters in Table 3 have not been defined earlier: $s_{d}$ is the diagonal center-to-center distance between piles $s_{d}=\sqrt{s_{x}^{2}+s_{y}^{2}}$, and $E_{\text {crown }}$ and $E_{\text {pile cap }}$ are Hewlett and Randolph's (1988) pile efficacies, as defined in Table 1, calculated assuming equilibrium for the crown element (Table 3f, left hand side) and at the pile cap (Table 3f, right hand side) respectively. The minimum efficacy value, $E_{\min }=\min \left(E_{\text {crown }}, E_{\text {pile cap }}\right)$, and its corresponding failure mode controls and determines the load on the reinforcement.

Researchers and engineers agree that a minimum height (often the critical height) should be required by practical design guidelines to prevent differential settlement at ground surface. Han (2015) summarized the suggested critical heights proposed by different researchers or standards. Section 3.2 summarizes the practical limitations for embankment heights and deformations in design methods and standards. Table 4 lists the required and recommended minimum embankment heights for design purposes.

\subsection{Shape of arches}

Several researchers have investigated arch shapes. Chew et al. (2006), Ariyarathne and Liyanapathirana (2014), Yapage et al. (2012), and Chen et al. (2016) used numerical analyses. Chen et al. (2016) and Bian et al. (2017) used large-scale experiments and Rui et al. (2019a) conducted small-scale experiments. In the experimental studies, the soil displacements are usually analyzed to observe the shape of the arch. In most numerical studies, however, the researchers evaluated the changes in vertical stresses with depth. Without arching, the vertical stress increases with depth. With arching, the vertical stress along a vertical line at the mid-span between the piles is usually found to decrease with depth, as shown experimentally by Zaeske (2001), and it increases again at larger depths in some studies. Yapage et al. (2012) found this numerically and defined the shape of the arch as follows: the top of the largest arch is found at the location where the vertical stress starts to decrease, and the top of the smallest arch starts where the vertical stress starts to increase again. All these researchers found that the highest arches are higher than circular arches; and some researchers found that the smaller arches are elliptical and lower than circular arches, as shown in the experiments of Rui et al. (2019a) (also see Figure 8).

Van Eekelen et al. (2015, shown in Figure 15) showed that the reinforcement tensile strains calculated using the Concentric Arches model in Figures 4 and 5 agreed very well with more than 100 data points from field measurements and series of full- and small-scale experiments found in different publications. This model was later confirmed by several researchers, including Lee et al. (2020), who conducted large-scale experiments, Lu et al. (2020), who presented field measurements from a widened highway embankment, Shen et al. (2018), who conducted 3D numerical analyses, and Lehn et al. (2016), who concluded that the basic idea of the Concentric Arches model (Table 3b) is more realistic than the approach of EBGEO (Table 3c) under both static and cyclic loading.

Several researchers specifically studied the development of soil arching during actual or simulated ongoing subsoil consolidation. They include Lai et al. (2014), Iglesia et al. (2014, without reinforcement), Rui et al. (2016a 2016b, 2018, without reinforcement), Rui et al. (2019a, with reinforcement), and King et al. (2017a 2017b, with reinforcement). This subject will be further discussed in Section 3.4.

\subsection{Factors influencing soil arching}

\subsubsection{General descriptions}

Many researchers have investigated the influence of several factors on stress distribution, including soil arching in GRPS embankments. They have used 2D experiments (Low et al. 1994; Chen et al. 2008b; Hong et al. 2014; Rui et al. 2019a, 2019b; Aqoub et al. 2020), 3D experiments (Zaeske 2001; Heitz 2006; Oh and Shin 2007; Van Eekelen et al. 2012a, 2012b; Chen et al. 2016; $\mathrm{Xu}$ et al. 2016; Lee et al. 2020), 2D numerical analyses (Han and Gabr 2002; Le Hello and Villard 2009; Zheng et al. 2009; Girout et al. 2014; Yapage and Liyanapathirana 2014), 3D numerical analyses (Van der Peet and Van Eekelen 2014; Pham et al. 2020; Wijerathna and Liyanapathirana 2020; Zhuang et al. 2020), 2D centrifuge tests (Iglesia et al. 2014; Da Silva et al. 2016), 3D centrifuge tests (Blanc et al. 2014; Girout et al. 2016; Fagundes et al. 2017; Almeida et al. 2020; Reshma et al. 2020; Shen et al. 2020a), field measurements (Van Eekelen et al. 2007, 2010, 2012c, 2020; Van Duijnen et al. 2010; King et al. 2017a, 2017b; Khansari and Vollmert 2020; Lu et al. 2020), 2D analytical calculations (Deb and Mohapatra 2013) and 3D analytical analyses (Van Eekelen et al. 2012b; Van Eekelen et al. 2013; McGuire et al. 2020; Pham 2020). The conclusions from the above studies are summarized below.

\subsubsection{Geometry}

- A higher fill with wider pile caps or smaller pile spacing results in the direct transfer of a higher load onto the piles and a reduction in the load exerted on the reinforcement and/or the subsoil between the piles. 
- Most researchers limit their studies to rectangular pile patterns. Exceptions include Wachman et al. (2010), Sloan (2011), Xing et al. (2014), Zhang et al. (2016), Wijerathna and Liyanapathirana (2020), and Zhang et al. (2019). This factor will be discussed in further detail in Section 3.2.2.

\subsubsection{Fill quality}

- Soil arching increases with higher-quality fill with a larger friction angle. Even though cohesion can increase soil arching, cohesion is not commonly used because it may not be reliable in the long term. See Section 3.2 for more detail.

\subsubsection{Differential settlement (subsoil consolidation)}

- Soil arching first increases and then degrades with increasing differential settlement of the subsoil/reinforcement. Section 3.3 shows that the degradation may be reduced or even eliminated by the use of reinforcement. This also indicates that the arching is more stable in GRPS embankments than in CPS embankments. See Section 3 for more detail.

\subsubsection{Stiffness and number of geosynthetic reinforcement layers}

- Stiffer reinforcement reduces deformation but has a limited effect on arching behavior (Van Eekelen et al. 2013; Pham 2020).

- Multiple geosynthetic layers (up to three layers) with small spacing, or none, between the layers behave as a single layer, with total tensile stiffness and strength being equal to the summed stiffnesses and strengths of the individual layers if the embankment height allows the full development of soil arching (Van Eekelen and Bezuijen 2014; Zhang et al. 2017).

\subsubsection{Surface loading}

- A higher static uniform surcharge load results in more arching (higher $A \%$ ), probably due to the higher effective stresses and greater differential settlement between piles and subsoil, as shown numerically for example by Van der Peet and Van Eekelen (2014). This finding contradicts most of the analytical models available in the literature.

- A cyclic load can have a different effect on soil arching, and localized surface loading degrades soil arching more than uniform surcharge loading. These effects will be discussed in Section 2.5.3.

Several analytical models, such as Zaeske (2001) (adopted in EBGEO (2010)), and Van Eekelen et al. (2013) and Van Eekelen et al. (2015) (adopted in Van Eekelen and Brugman, 2016), can describe most of the factors listed in this section. The exceptions are the influence of the static surcharge load and the subsoil consolidation or reinforcement deflection. Both EBGEO (2010) and Van Eekelen and Brugman (2016) consider the long-term condition for the design of GRPS embankments. The effect of subsoil consolidation on soil arching is considered by Deb (2010), Filz et al. (2012, 2019), and King et al. (2017a, 2017b).

\subsubsection{Effect of geosynthetic reinforcement}

Several researchers have investigated the effect of reinforcement on the load distribution in pile-supported embankments. If no reinforcement is used, the load distribution on the subsoil between the piles is not inverse-triangular but more uniform, as shown by Zaeske (2001) and Xing et al. (2014), and as explained and validated by Van Eekelen et al. (2015). This distribution is the result of the approximately uniform subsoil support and settlement of the subsoil. This is different from the smooth curved shape of the deflected reinforcement, which induces soil arching of a different character and makes it more efficient. Aqoub et al. (2020) conducted 2D experiments and found that the inclusion of reinforcement enhanced the concentration of stresses on the pile caps when the fill was subjected to cyclic loading. Briançon and Simon (2012) conducted full-scale field experiments on a 5 m-high embankment, which were simulated numerically by Rowe and Liu (2015). Rowe and Liu (2015) concluded that the use of reinforcement in these field experiments reduced the reinforcement differential settlement by 62 to $68 \%$ and the maximum crest settlement by 32 to $37 \%$ by comparison with a CPS embankment. Aqoub et al. (2020) found a reduction of the surface settlement by 18 to $41 \%$ depending on the number of reinforcement layers.

Using large-scale experiments, Lee et al. (2020) showed nicely why soil arching is more stable when reinforcement is used in a piled embankment. They found that arching in a CPS embankment eventually decreases because of increased static loading, while this is not the case when reinforcement is used. This result complies with that obtained by Bhandari (2010) in his DEM analysis. Furthermore, Heitz (2006) has shown that the use of reinforcement considerably reduces the susceptibility of soil arching to damage caused by cyclic loading (see Section 2.5.3).

\subsubsection{Effect of surface loading}

The effect of uniform static surface loading (i.e. surcharge) on soil arching has been investigated at least since Terzaghi (1936). There have been an increasing number of studies on the effect of cyclic loading. This paper uses the term 'cyclic loading' for traffic loading. Cyclic loading to simulate traffic loading often has a repeated load wave with a fixed load magnitude and a fixed frequency for a given time duration or number of cycles. The influence of cyclic loading on soil arching has been studied in laboratory tests, field monitoring, and numerical analyses in recent years. A brief review of some of these studies is given below. 


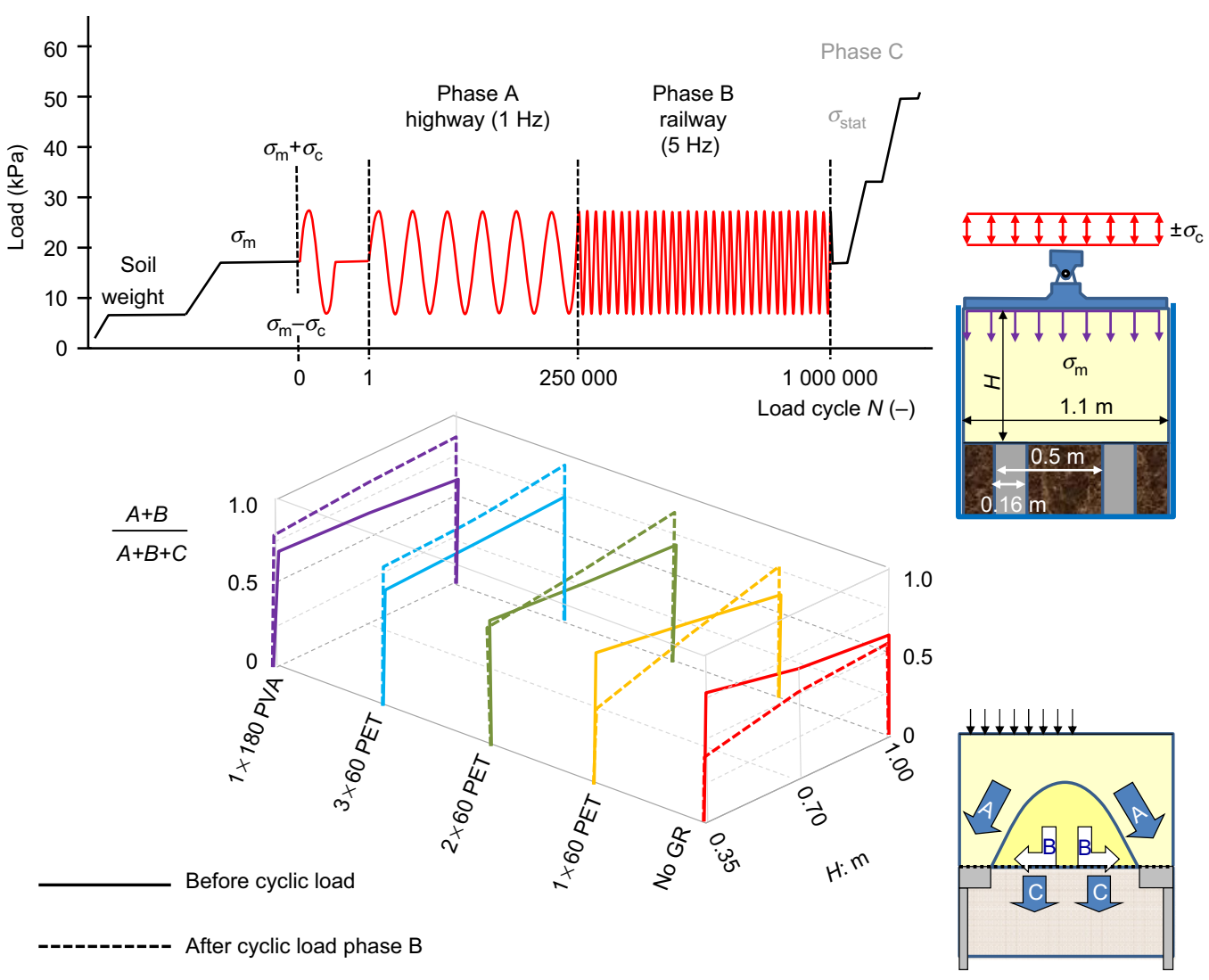

Figure 9. Results of 3D experiments: the influence of geosynthetic reinforcement and embankment height $\boldsymbol{H}$ on the level of arching under cyclic loading (modified after Heitz 2006)

\subsubsection{Development, degradation, stabilization, enhancement and recovery of arching}

Cyclic loading has different effects on soil arching. Field measurements show that cyclic loading within the early weeks or months of construction enhances arching (Van Eekelen et al. 2007, 2012c, 2020; Haring et al. 2008; Van Duijnen et al. 2010), probably because of the densification of the embankment fill and the induced settlement of the subsoil. This is also why engineers tend to recommend driving vehicles across a piled embankment under construction.

Heitz (2006), Al-Naddaf et al. (2017, 2019a, 2019b), Aqoub et al. (2020) and Xu et al. (2019) conducted 3D and 2D reduced-scale experiments under static and/or cyclic loading while Van Eekelen et al. (2007, 2010), Chen et al. (2016) and Bian et al. (2017) reported the results of full-scale experiments. They all showed that cyclic loading degraded arching. Xu et al. (2019) showed that the effect on degradation increased with the loading magnitude and the loading frequency.

Heitz (2006), Chen et al. (2016) and Aqoub et al. (2020) showed that most arching degradation took place during the first cyclic loading phase and then arching stabilized, or was even enhanced, under further cyclic loading.

Furthermore, they showed that arching recovered during a rest period. This latter phenomenon was also found in field measurements by Van Eekelen et al. (2007, 2010) and the 2D laboratory tests by Xu et al. (2019). Xu et al. (2019) found that soil arching could recover after unloading in a high embankment but could not recover after unloading in a low embankment.

Heitz (2006) showed (see Figure 9) that increasing the embankment height or using reinforcement minimized the degradation of soil arching due to cyclic loading. He even showed that, if the embankment is high enough or if sufficiently stiff reinforcement is used, arching is actually enhanced by cyclic loading. Aqoub et al. (2020) confirmed this finding by showing that the inclusion of reinforcement enhances the load transfer to the piles by soil arching and reduces the surface settlement due to cyclic loading.

Heitz (2006) developed a calculation method using an arching reduction factor $(\kappa)$ that reduces the arching for high cyclic loading. His method was based on unreinforced tests and neglects the recovery of arching during a rest period; it is therefore conservative and results in safe design. This method was adopted in the design guideline Van Eekelen and Brugman (2016).

The findings of Heitz (2006) were also confirmed numerically by Pham et al. (2020) with a 3D numerical analysis. Pham et al. (2020), who conducted 3D numerical analyses using an advanced constitutive model based on the hypo-plasticity concept. This model makes it possible to describe cumulative strain during subsequent loading cycles. These researchers showed that the presence of reinforcement reduced the rate of reduction in the arching effect in the embankment fill and reduced accumulated settlement. The rate of settlement accumulation decreased with the number of load cycles. The number of 
reinforcement layers did not appear to affect soil arching or the accumulated settlement.

\subsubsection{Localized loading}

Bhandari (2010) conducted a 2D discrete element method (DEM) study with a footing load on the embankment fill and found that cyclic loading reduced the stress concentration ratios for both pile-supported embankments with and without reinforcement, and that reinforcement minimized the reduction of the ratio. Al-Naddaf et al. (2019a) conducted 2D reduced-scale model tests to investigate the effects of localized static and cyclic surface loading using a footing on an embankment fill over a compressible geofoam on the top of a concrete culvert in the laboratory. They found that the compressible geofoam (similar to compressible subsoil in pile-supported embankments) enhanced soil arching above the geofoam and reduced the vertical stress on the concrete culvert. Localized cyclic loading induced a higher soil arching ratio (defined in Table 2) on the culvert than localized static loading. In other words, cyclic loading resulted in more degradation of soil arching than static loading.

\subsubsection{Train speed on railway tracks}

Chen et al. (2016) and Bian et al. (2017) conducted full-scale high-speed experiments. They showed that most cyclic loading goes directly to the pile caps and that the load on the pile caps increases with increasing train speed. The load on the reinforcement, however, is negligibly small and does not change much as a result of a higher train speed.

Bian et al. (2017) also carried out 3D numerical analyses which were validated using data from their experiments. They showed that, in the case of unballasted slab track, the cyclic load on the pile top increases by approximately $20 \%$ when train speed increases from 10 to $100 \mathrm{~m} / \mathrm{s}$. But the increase in speed does not alter the pattern of cyclic soil stress distribution. In addition, they showed that the pile beneath the track center is subjected to more cyclic loading than its neighboring piles in the transversal direction. Bian et al. (2017) also showed that railway embankments have a much higher soil arch in a ballasted track than in an unballasted slab track. This shows that the higher load-spreading capacity of the slab results in lower stresses and smaller levels of differential movement underneath the slab, and therefore less arching. In addition, they showed that the soil arch heights caused by a static load and moving train loads at different speeds are similar.

\section{PRACTICAL DESIGN}

\subsection{Introduction}

This section discusses several factors relating to the design of GRPS embankments in practice. Each sub-section considers one factor and includes but is not limited to the conclusions resulting from the First International Workshop on Geosynthetic-Reinforced Pile-Supported Embankments (see Supplemental Material)).

\subsection{Requirements and limitations}

\subsubsection{Height of the embankment}

It is generally believed that no differential settlement will occur at ground surface if the height of an embankment is higher than or equal to the critical height $H_{\text {crit }}$. Quite a lot of research has focused on the issue of critical height, examples being Demerdash (1996), Chen et al. (2008b 2010); Ellis and Aslam (2009a, 2009b), Costa et al. (2009), Britton and Naughton (2010), McGuire et al. (2012) and Sloan (2011). Han (2015) summarized the suggested critical or minimum heights proposed by different researchers or standards. Table 4 shows an extended table from the study by Han (2015). Furthermore, the participants at the workshop (see Supplemental Material) agreed that no GRPS embankment should be constructed with a height $H$ less than $0.66\left(s_{d}-d\right)$, which is in line with the requirements of Van Eekelen and Brugman (2016).

Reduced and partial arching may occur in an embankment lower than the critical height. Table 3 lists different types of arching, which are dependent on the embankment height. Van Eekelen and Brugman (2016) also considers partial arching for lower embankments (see Table 3) and allows a minimum embankment height that is lower than the critical height $\left(H_{\min }=0.66 \cdot\left(s_{d}-d\right)<\right.$ $H_{\text {crit }}=0.5 \cdot s_{d}$ which occurs for $\left.a>0.3 \cdot s_{x}\right)$. In addition, this guideline specifically considers the differential settlement that occurs after the installation of a pavement or railway by limiting the in-service reinforcement strain, which is calculated as the difference between the average serviceability limit state (SLS) strain at the end of the service life and the average SLS strain immediately after the construction of the road (see Section 3.2.3).

\subsubsection{Pile pattern}

Hong et al. (2014) show that pile spacing should be limited if soil arching is considered in the design. If pile spacing is too large, adjacent piles do not interact with each other and there is no arching. In these circumstances, pile head punching into the fill occurs. Van Eekelen and Brugman (2016) limits the center-to-center pile spacing to $2.50 \mathrm{~m}$ since no measurements were available to validate this design method for larger pile spacing. Different methods have different requirements for maximum center-to-center pile spacing. One method states that it should not exceed three times the pile cap width $a$ (Hewlett and Randolph 1988), while others adopt a limit of 6.7·a $\left(s_{x} / a \leq 1 / 0.15\right)$ (EBGEO 2010; Van Eekelen and Brugman, 2016). Another approach limits the pile spacing by the requirement for a minimum embankment height (see Section 3.2.1 and Table 3).

Most design methods are based on square or rectangular pile patterns, although the FHWA manual (Schaefer et al. 2017) and EBGEO (2010) do consider triangular pile patterns. Square or rectangular pile patterns work better with uniaxial or biaxial reinforcement geosynthetics and can be analyzed easily. Van Eekelen and Lodder (2016) specifically look at rectangular pile arrangements (i.e. $s_{x} \neq s_{y}$ ) and show that EBGEO (2010) and Zaeske (2001) require less stiff and strong reinforcement in the direction with the larger pile spacing. The 


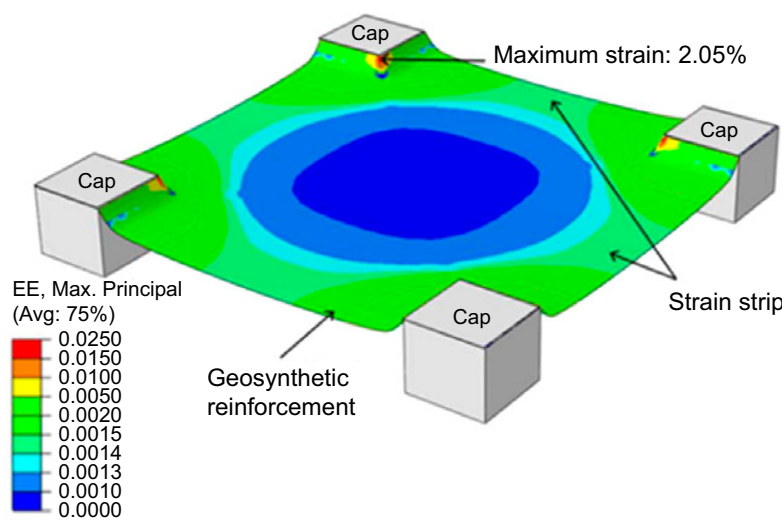

(a)

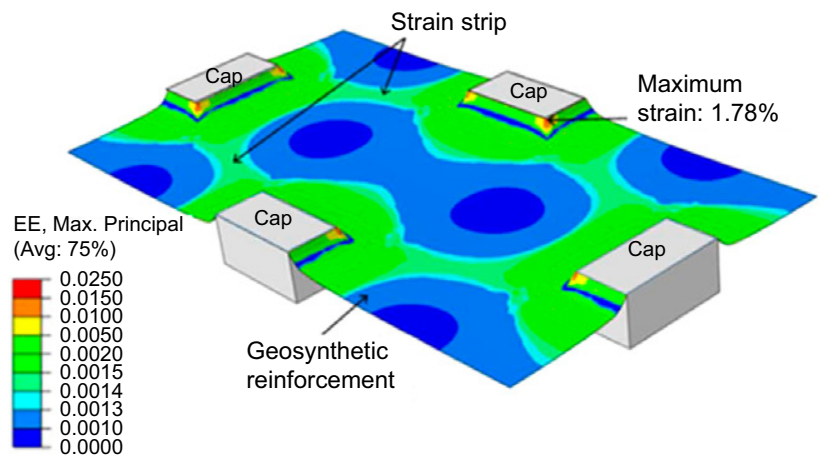

(c)

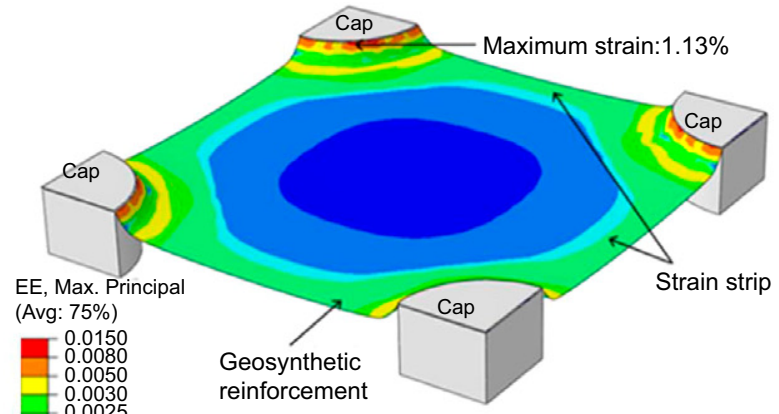

(b)

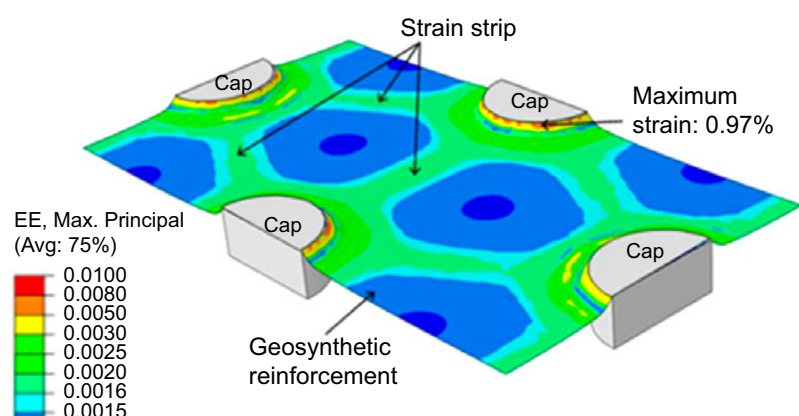

(d)

Figure 10. Effect of pile cap shape and pattern on maximum principal tensile strain distributions in the geosynthetic reinforcement (the legend is the maximum principal tensile strain in the reinforcement: (a) Square pile caps in a square pattern; (b) circular pile caps in a square pattern; (c) square pile caps in a triangular pattern; (d) circular pile caps in a triangular pattern (Zhang et al., 2019)

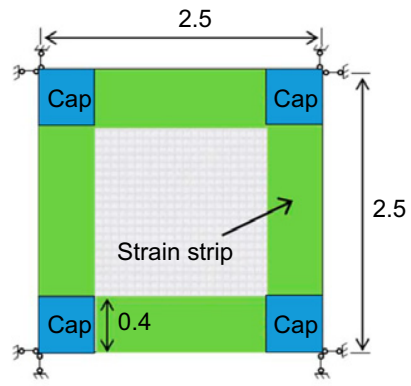

(a)

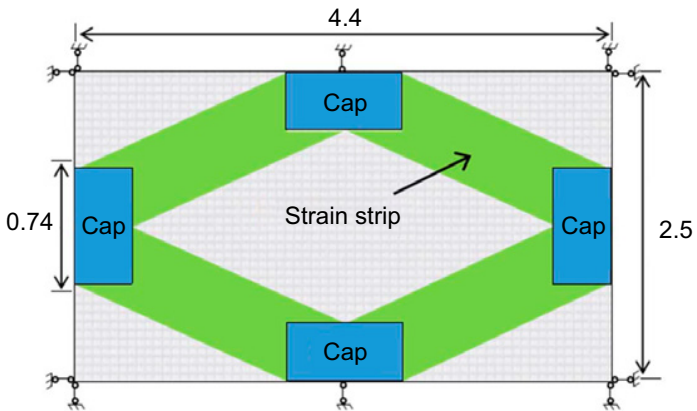

(b)

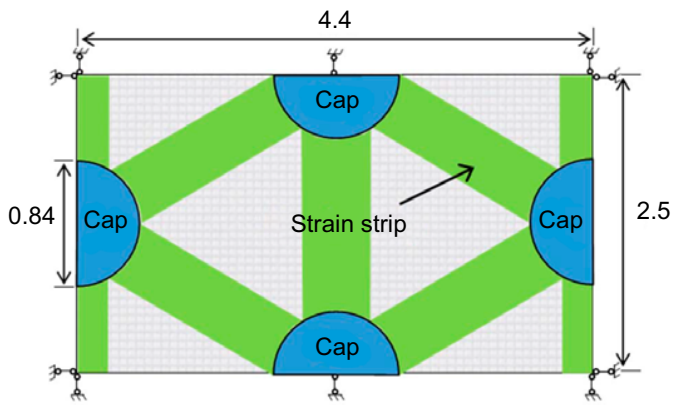

(c)

Figure 11. Tensile strain in the geosynthetic reinforcement strips over square or circular pile caps in a square or triangular pattern (unit: m): (a) Square or circular pile caps; (b) square pile caps in a triangular pattern; (c) circular pile caps in a triangular pattern (Zhang et al. 2019) 
Table 5. Minimum cap coverage

\begin{tabular}{|l|l|l|}
\hline & Minimum size of pile cap & $\begin{array}{l}\text { Minimum degree of } \\
\text { cap coverage }\end{array}$ \\
\hline $\begin{array}{l}\text { Standards and design guidelines, GRPS embankments } \\
\text { British Standard BS8006 (BSI 2010) }\end{array}$ & $\begin{array}{l}\text { Size of pile cap may be determined according to the minimum clear span } \\
\text { requirement: } 0.7\left(s_{x}-a\right) \leq H \text { for square pattern } \\
\text { als } \geq 0.15\end{array}$ & - \\
$\begin{array}{l}\text { Dutch Design Guideline CUR226 } \\
\text { FHWA (Schaefer } \text { et al. 2017) } \\
\text { requirement: } 1.2\left(s_{x}-a\right) \leq H \text { for square pattern; } 1.4\left(s_{x}-a\right) \leq H \text { for isosceles } \\
\text { pattern; } 1.5\left(s_{x}-a\right) \leq H \text { for triangular pattern }\end{array}$ & - \\
$\begin{array}{l}\text { German Standard EBGEO (2010) } \\
\begin{array}{l}\text { Nordic Guidelines for Reinforced } \\
\text { Soils and Fills (NGG 2004) }\end{array}\end{array}$ & $3.5 \%$ \\
$\begin{array}{l}\text { Recommendation of researchers, CSP embankments } \\
\text { Rathmayer (1975) }\end{array}$ & $10 \%$ \\
\hline
\end{tabular}

Note: $a=$ pile cap width; $d=$ pile cap diameter; $s_{x}=$ center-to-center spacing between piles; and $s_{d}=$ center-to-center spacing between piles in the diagonal direction.

Table 6. Recommended or required maximum geosynthetic reinforcement strains from different sources (modified from Lawson 2012)

\begin{tabular}{|c|c|c|c|}
\hline Source & Basis & Values & Boundary conditions \\
\hline British BS8006-1 (BSI 2010) & Past experience & $\begin{array}{l}\text { Total strain: } \leq 5-10^{\mathrm{a} o} \% \text { (typically } \leq 6 \% \text { ); } \\
\text { strain during serviceability } \\
\text { phase: } \leq 3 \%\end{array}$ & No foundation support \\
\hline Chew et al. (2006) & Large-scale physical modelling & $\leq 4 \%$ & No foundation support \\
\hline Kempton et al. (1998) & 3D numerical modelling & $\leq 4 \%$ & Dependent ${ }^{\mathrm{b}}$ \\
\hline EBGEO (2010) & Past experience & $\leq 6 \%$ & Dependent $^{\mathrm{b}}$ \\
\hline Halvordson et al. (2010) & 3D numerical modelling & $\leq 3 \%$ & Dependent $^{\mathrm{b}}$ \\
\hline $\begin{array}{l}\text { Dutch CUR226 } \\
\text { (Van Eekelen and Brugman, 2016) }\end{array}$ & Past experience & $\begin{array}{l}\text { Total strain: } \leq 2-5 \% \\
\text { during serviceability phase: } \leq 1-3 \%\end{array}$ & Dependent ${ }^{\mathrm{b}}$ \\
\hline FHWA (Schaefer et al. 2017) & Past experience & $<5 \%$ & Dependent ${ }^{\mathrm{b}}$ \\
\hline $\begin{array}{l}\text { Nordic Guidelines for Reinforced } \\
\text { Soils and Fills (NGG 2004) }\end{array}$ & & $\begin{array}{l}\text { Initial strain } \leq 6 \% \\
\text { strain during serviceability phase: } \leq 2 \% \\
\text { total strain } \leq 70 \% \text { of geosynthetic } \\
\text { reinforcement failure strain. }\end{array}$ & - \\
\hline French ASIRI (2012) & & $\begin{array}{l}\text { For } H>0.7(s-a) \text { : total strain } \leq 6 \% \\
\quad \text { For } H \leq 0.7(s-a) \text { : total strain } \leq 3 \% \text {; } \\
\text { post-construction strain } \leq 2 \%\end{array}$ & - \\
\hline
\end{tabular}

${ }^{a}$ Many GRPS embankments are constructed using geosynthetics with rupture strains close to or smaller than $10 \%$. In that case, the ultimate strain limit will govern rather than the $10 \%$ strain limit.

${ }^{\mathrm{b}}$ Dependent on reinforcement type, embankment geometry, and nature of subsoil support

Concentric Arches model of (Van Eekelen et al. 2013 and Van Eekelen et al. 2015) requires stiffer and stronger reinforcement in the direction with the larger pile spacing, which seems more reasonable.

Some researchers have reported field measurements of GRPS embankments with triangular pile patterns, examples being Wachman et al. (2010), Xing et al. (2014), Zhang et al. (2016), Wijerathna and Liyanapathirana (2020), and Zhang et al. (2019). A limited number of studies have been published about the comparison between rectangular or square and triangular pile patterns. 3D ABAQUS calculations conducted by Wijerathna and Liyanapathirana (2020) showed that a square pile pattern results in lower vertical pressure on the reinforcement, indicating more efficient arching than a triangular pile pattern with the same replacement ratio. Furthermore, they found $25 \%$ less ground surface settlement for the triangular pile pattern. Typically, soil arching is mobilized more at larger displacement. In other words, a square pattern leads to more soil arching and more ground surface settlement.

Zhang et al. (2019) conducted a 3-D numerical study of the effects of pile cap shape and pattern on tensile strain distributions in reinforcement. They modeled geosynthetic reinforcement as an orthotropic linear elastic material with a tensile stiffness of $1400 \mathrm{kN} / \mathrm{m}$ in both orthotropic directions. Figure 10 shows that the maximum tensile strains occurred at the corner of square pile caps and along the edge of circular pile caps. The circular pile caps reduced the maximum tensile strains in the reinforcement to approximately half by comparison with square pile caps. These results are fully in line with the findings of Jones et al. (2010) and Halvordson et al. (2010). The triangular pile cap pattern further reduced the maximum tensile strains in the reinforcement by approximately $15 \%$. In other words, circular pile caps in a triangular pattern in 
Figure 10d resulted in the lowest maximum tensile strains in the reinforcement. On the basis of the tensile strain distributions in the reinforcement, Zhang et al. (2019) proposed the strain strip concept (in other words, the maximum strain concentrated on this strip), as shown in Figure 11, and a semi-empirical relationship to estimate the maximum tensile strain considering the pile cap shape and pattern effects.

Table 5 lists the requirements and recommendations for the minimum pile cap coverage.

\subsubsection{Deformation requirements}

Reinforcement strain or reinforcement deflection, which can be calculated analytically, are subject to limits in some design guidelines or standards. Other guidelines include requirements for column settlement or differential settlement at the reinforcement level or at ground surface. Lawson (2012) reported the required reinforcement strain limits from different sources. Table 6 shows an extended version of this list from Lawson (2012). The exact magnitude of the allowable strain depends on the project owner or owner representative, the reinforcement type, the embankment geometry, and the nature of subsoil support. The in-service reinforcement strain is calculated by subtracting the average SLS strain immediately after construction from the average SLS strain at the end of the service life. Between these two states in time, changes occur in terms of geosynthetic behavior, surcharge load, and subsoil support. Note that the Dutch guideline CUR226 limits the average reinforcement strains while the British standard and EBGEO limit the maximum reinforcement strains. As the reinforcement strains are not uniform, these strain limits may be different.

Han (2015) suggested limiting the maximum reinforcement deflection to $0.15 \mathrm{~m}$. France (ASIRI 2012) limits differential settlement at ground surface, which should be calculated numerically.

To the authors' best knowledge, no guidelines limit the normalized reinforcement deflection $\left(s_{G R} /\left(s_{d}-a\right)\right)$ where $s_{G R}$ is the maximum deflection of the reinforcement. Rui et al. (2019b) relate the reinforcement deflection to the differential settlement at ground surface.

Lawson (2000) recommended a maximum allowable differential surface settlement (also called surface distortion) of $1 \%$ for highway pavements, which is defined as the percent of the surface differential settlement divided by the horizontal span between piles. Lawson (2000) pointed out that higher-quality highways may require a more stringent criterion. Ling et al. (2003), as reported by Han et al. (2007), suggested the use of the maximum allowable surface distortion of $0.4 \%$ to avoid possible cracking between existing and widened embankments. On the basis of the numerical analysis of GRPS embankments over voids, Lawson (2000) developed a design chart to estimate the required embankment height-pile cap clear spacing ratio, $H /\left(s_{x}-a\right)$, at different allowable levels of differential surface settlement and geosynthetic reinforcement stiffness $J$. On the basis of this design chart, the $H /\left(s_{x}-a\right)$ ratio of 1.7 or greater and $J=4000 \mathrm{kN} / \mathrm{m}$ or higher are required to meet the maximum allowable

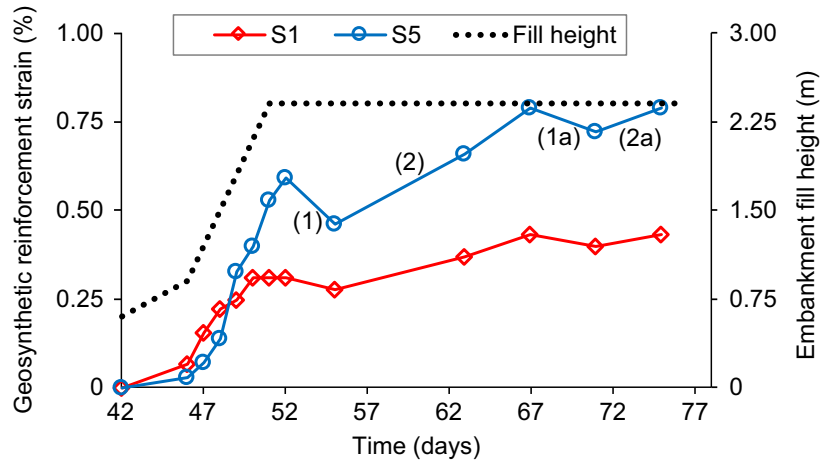

Figure 12. Geosynthetic reinforcement tensile strains measured during and after placing the embankment on floating piles (after Cao et al. 2016)

surface distortion of $1 \%$. Lawson (2000) also pointed out that the minimum required limit of $H /\left(s_{x}-a\right)$ of 0.7 suggested by the BS8006-1: 2010 (BSI 2010) would result in approximately $4 \%$ surface distortion, which is excessive for most pavement applications.

\subsubsection{Floating piles and pile stiffness relative to surrounding soil}

Piles should be stiff enough with respect to the surrounding soil to ensure soil arching in the embankment fill. Han and Gabr (2002) showed that an increase of pile modulus reduced the soil arching ratios for both CPS and GRPS embankments and the rate of increase fell after reaching a critical pile modulus value. Most of the current soil arching models are based on rigid supports and are valid for end-bearing piles when the pile to soil modulus (stiffness) ratio is greater than a certain value. Van Eekelen and Brugman (2016) suggests a pile-soil stiffness ratio $k_{p} / k_{\mathrm{s}}>10$; EBGEO (2010): $k_{p} / k_{\mathrm{s}}>75$; Han (2015): $k_{p} / k_{\mathrm{s}}>100$, where $k_{p}\left(\mathrm{kN} / \mathrm{m}^{3}\right)$ is the pile stiffness. $k_{p}$ is defined as: $k_{p}=(A+B) /\left(s_{\mathrm{p}} \cdot A_{\mathrm{p}}\right)$, where $A+B(\mathrm{kN} / \mathrm{pile})$ is the total load on the pile cap (see Figure 6), $s_{\mathrm{p}}(\mathrm{m})$ is the settlement of the pile cap, and $A_{\mathrm{p}}\left(\mathrm{m}^{2}\right)$ is the pile cross-sectional area. It is clear that there is no agreement about the limit at this time. The authors of this paper believe that soil arching may be taken into account if the pile-soil modulus ratio is 50 to 100 or larger. Soil arching should therefore not be considered for stone columns, which typically have a modulus of 10 to 20 times their surrounding soil. For geosynthetic-encased columns, soil arching may or may not be considered depending on the stiffness ratio of the columns with respect to the surrounding soil. However, deep mixed columns typically have a modulus of 50 to 100 times the surrounding soil. In that case, the authors believe that soil arching may be considered here.

Floating (frictional) piles are rarely used for GRPS embankments, except in a limited number of countries (such as China and India), even though these piles are more economical and technically feasible in areas with thick soft soil layers than end-bearing piles. Several researchers have studied the behavior of GRPS embankments with floating piles. Cao et al. (2016) monitored field embankments supported by floating piles for 32 months 
and measured the reinforcement strains between adjacent pile caps (S1 and S5 in Figure 12). During the resting period between embankment filling and surcharge loading, they found a short-term decrease in reinforcement strains followed by a gradual increase. They explained this behavior as follows: (1) rapid filling of the embankment resulted in a downward movement of the floating piles and subsequently in a decrease in the differential settlement between the pile caps and the slowly-consolidating subsoil and a reduction in reinforcement strain and (2) after pile settlement, part of the load previously borne by the piles was transferred to the subsoil, resulting in turn in the subsequent increase in reinforcement strains. This process repeated subsequently as noted in 1a and 2a in Figure 12.

Chen et al. (2008a), Satibi (2009), and Bhasi and Rajagopal (2015) conducted numerical analyses of GRPS embankments with floating piles. $\mathrm{Xu}$ et al. (2016) conducted reduced-scale model tests on GRPS embankments with floating piles while Reshma et al. (2020) and Shen et al. (2020a) conducted centrifuge tests on embankments with floating and end-bearing piles. All these researchers found that the use of floating piles can reduce the settlement of the embankments considerably by comparison with embankments without piles. The reduction in the settlement of a pile-supported embankment is related to the 'composite' stiffness of the combination piles/soft foundation. The higher the composite stiffness (the number, size and extent of piles), the lower the settlement. Satibi (2009) concluded that the most cost-effective construction is achieved when the ratio of pile length to the soft soil thickness is between 0.3 and 0.5 . However, he suggested a careful consideration of the corresponding embankment settlement since, at these pile lengths, the settlement of the embankment may be significant. Shen et al. (2020a) proposed a method to estimate the settlement of GRPS embankments with floating piles by treating the floating piles and the soil in between as an equivalent pier (similar to a pile group). Liu and Rowe (2015) combined floating piles with prefabricated vertical drains to meet the requirement of $100 \mathrm{~mm}$ post-construction crest settlement for a bridge approach embankment.

The numerical analysis by Bhasi and Rajagopal (2015) showed that the length of the piles affected soil arching strongly, and that shorter piles resulted in less soil arching. $\mathrm{Xu}$ et al. (2016) conducted six reduced-scale model tests and also showed that floating piles result in less soil arching because the difference in stiffness between the piles and surrounding soil was limited.

\subsubsection{Negative skin friction}

Chen et al. (2008a) developed a one-dimensional compression method based on a unit cell concept considering negative skin friction in the upper portion of floating or end-bearing piles. This method was compared with numerical results and gave reasonable agreement. The load-displacement compatibility (LDC) method (Filz et al. 2012, 2019) considers load transfer from the foundation soil to the piles by negative skin friction. The
French design guideline (ASIRI 2012) includes negative skin friction along piles in reinforcement design when pile caps are not used. Shen et al. (2020a) considered negative skin friction in settlement calculations for embankments on end-bearing and floating piles. Rui et al. (2020) proposed a simplified method to estimate vertical stresssettlement responses of pile-supported embankments on soft soils considering the negative skin friction effect. In recent years, there has been an increased number of field studies to assess negative skin friction distribution and its effect on pile capacity and settlement (examples being Gallant et al. 2018; Sloan et al. 2019; Chow et al. 2020).

\subsubsection{Water}

In natural peat deposits, water tables may be as high as 0.10 to $0.20 \mathrm{~m}$ below the surface. In urbanized delta areas with soft soil, the water table is often around 0.50 to $0.70 \mathrm{~m}$ below the surface. In these areas, road surfaces are often built at relatively low elevations to ensure that the road does not jar with the surroundings and to prevent connection problems with the surrounding area. This leaves limited space for the construction of pile-supported embankments above the water table. This resulting limited embankment height requires the limitation of pile spacing so that the differential settlement at the bottom of the embankment will not be reflected to the road surface. Project owners or owner representatives sometimes therefore wish to place the majority of the embankment section below the water table to create more space allowing construction of a higher embankment so that larger pile spacing is possible and less piles are needed.

However, such a high water table, or a rise in the water table, flooding, heavy rainfall or artesian water, can affect the arching behavior due to the changes in fill properties, the reduction of effective stresses, and the increased weight or swell of the subsoil. Van Eekelen et al. (2012c), Briançon and Simon (2012), Sloan (2011), and Van Eekelen et al. (2020) all presented measurements showing that moisture affects arching behavior. Song et al. (2018) presented 2D trapdoor tests with sand under different water tables. They concluded that soil arching can degrade if the water table is located inside a zone of two times the trapdoor width above the trapdoor.

\subsection{Analytical models for arching}

Researchers have proposed several analytical models for soil arching in the literature. The Concentric Arches model shown in Figures 4 and 5 assumes that the loads follow the arches and that assumption was confirmed with numerical analyses by several researchers, including Van der Peet and Van Eekelen (2014), and Lehn et al. (2016). The well-validated Concentric Arches model (see Figure 15 for comparisons) is an extension of the models by Hewlett and Randolph (1988) and Zaeske (2001), who also proposed analytical models of different arches in which the loads follow the arches. These models belong to the family of limit state equilibrium models in which an imaginary limit-state stress arch is assumed to appear in the fill between the stiff elements. In the 3D situation, these stiff elements are piles; in the 2D situation, 
they are beams or walls. The vertical stress on the reinforcement $(B)+$ subsoil $(C)$ (see Section 2.2) is calculated by considering the equilibrium of the arch.

Rigid wedge arch models include several Scandinavian models (Carlsson 1987; Rogbeck et al. 1998 (modified by Van Eekelen et al. (2003)); Svanø et al. 2000), the Enhanced Arching model (also called the Bush-Jenner model in the UK or the Collin (2004) model in the US), and the 3D arch model of the Public Works Research Centre in Japan (PWRC 2000, also discussed in Eskişar et al. 2012). In this family of models, it is assumed that an arch is formed with a fixed shape. The shape of the arch is usually triangular in $2 \mathrm{D}$ or $3 \mathrm{D}$. These models assume that the entire load above the arch, including the soil weight and the traffic load, is transferred directly to the piles (load part A, or arching A, see Figure 4). The weight of the soil wedge is carried by the reinforcement + subsoil $(B+C)$. These models do not consider the mechanical properties of the fill, such as the friction angle, in their model equations and they have been used less after the development of the newer curved arches approach. They will therefore not be discussed further in the present paper.

Another family of arching models is the family of vertical slip plane frictional models. Several researchers have adopted the frictional model proposed by Terzaghi (1943), which was in turn based on the work done previously by other researchers, including Cain (1916) and Völlmy (1937). McKelvey (1994) extended the Terzaghi method by assuming that a 'plane of equal settlement' exists at $H_{\text {crit }}=3\left(s_{x}-a\right)$ and this method was combined with a tensioned membrane theory for geosynthetic reinforcement over voids by, for example, Giroud et al. (1990).

Russell and Pierpoint (1997) extended the Terzaghi model to include a third dimension by assuming the presence of friction in the vertical planes along the edges of the square pile caps. Chen et al. (2008a) developed an axisymmetric model with vertical slip planes and an equal settlement plane for end-bearing pile or floating pilesupported embankments. This method can calculate the negative skin friction induced by the compression of soft soil under embankment loading, a factor that is not considered by most of the design methods. However, Chen et al. (2008a) did not consider reinforcement in their method. McGuire et al. (2012) also adopted the idea of a 'plane of equal settlement' and described its corresponding height as the 'critical height'. They conducted laboratory tests and collected field data to determine and validate their equation for the critical height. Filz et al. (2012, 2019) used this critical height with the modified Terzaghi method by Russell and Pierpoint (1997). Naughton (2007) determined the critical height with log spiral shear planes. Britton and Naughton (2010) used 3D experiments to validate the critical height of their model.

Although the ideas underlying the frictional models are extremely important, these models are not commonly used in Europe for pile-supported embankments. A possible reason for the infrequent use of these models in Europe is that the results depend to a large extent on the lateral earth pressure coefficient of $K$ (the ratio between horizontal and vertical pressure). Different researchers have proposed different values for this $K$ value. Han et al. (2017) found that when $K=1.0$ is used, the Terzaghi method predicts the vertical stress on the $2 \mathrm{D}$ trapdoor without reinforcement satisfactorily when the displacement is equal to $10 \%$ of the trapdoor width.

A familiar empirical model is the Marston and Anderson (1913) model, which was modified by Jones et al. (1990) and then adopted in BS8006 and the Finnish design guideline (Liikennevirasto 2012). Marston and Anderson (1913) carried out numerous experiments and proposed a $2 \mathrm{D}$ equation to determine arching above a pipe in soil. This 2D equation was modified by Jones et al. (1990) for 3D pile-supported embankments, as explained and further modified in Van Eekelen et al. (2011a). This model is very important because of the widespread application of BS8006.

Another type of model that should be mentioned is the family of hammock models, such as the 'path of minor principal stress' model described by Handy (1985).

Some design methods ignore the foundation soil support under the reinforcement (in other words, it is treated as a void, as in BS8006); other models consider subsoil support but ignore its effect on soil arching, while other design methods consider the effect of foundation soil support on soil arching. Examples are the onedimensional model of Chen et al. (2008a), the plane-strain models of Deb (2010), Deb and Mohapatra (2013), and Zhang et al. (2012), and the coupled fill arching and subsoil consolidation model using the ground reaction curve of King et al. (2017a 2017b). Filz et al. (2012, 2019) model the fill, the reinforcement, the piles, and the subsoil as separate elements. The boundary condition for each of these elements is that the deformations between neighboring elements must match. This approach determines the load transferred to the piles directly (arching $A$, see Figure 4). Filz et al. (2012, 2019) limit arching $A$ with the 3D Terzaghi model (cross-shaped, according to Russell and Pierpoint 1997), considering a critical height. King et al. (2017b) support the use of limit state models, such as the Concentric Model for ULS calculations, but give an alternative for serviceability calculations in which soil arching depends on subsoil consolidation.

Iglesia (1991) and Iglesia et al. (1999, 2014) proposed a ground reaction curve (GRC) to describe the change of the average vertical stress in an unreinforced fill on a trapdoor with trapdoor displacement. This empirical GRC curve was developed on the basis of centrifuge tests without reinforcement. The curve describes four phases of soil arching (see also Section 2.3) as a function of geometric and material parameters: no arching, maximum arching, stress recovery, and ultimate arching as shown in Figure 13. King et al. (2017b) coupled this curve to the consolidation settlement of the soil between piles. Han et al. (2017) simplified the Iglesia (1991) curve into three linear lines and found that the average vertical stress on the 2D trapdoor without reinforcement predicted by the Terzaghi (1943) method occurred at the trapdoor normalized displacement of approximately $10 \%$ (i.e. trapdoor displacement divided by the trapdoor width). The change of the state of soil arching from no 


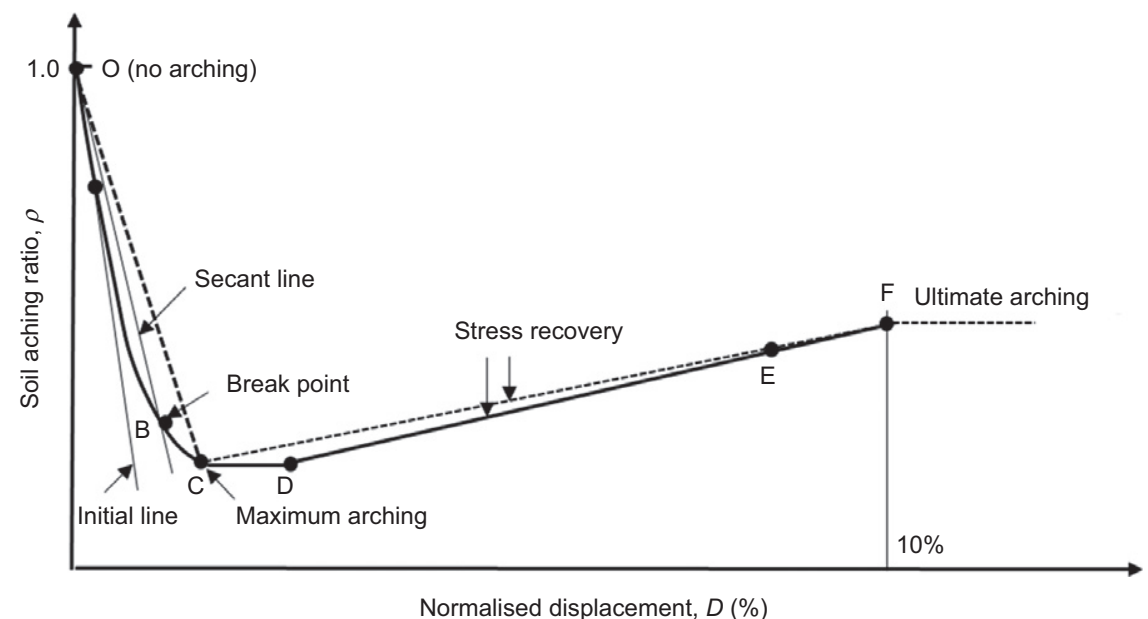

Figure 13. The Ground Reaction Curve (Han et al. 2019)

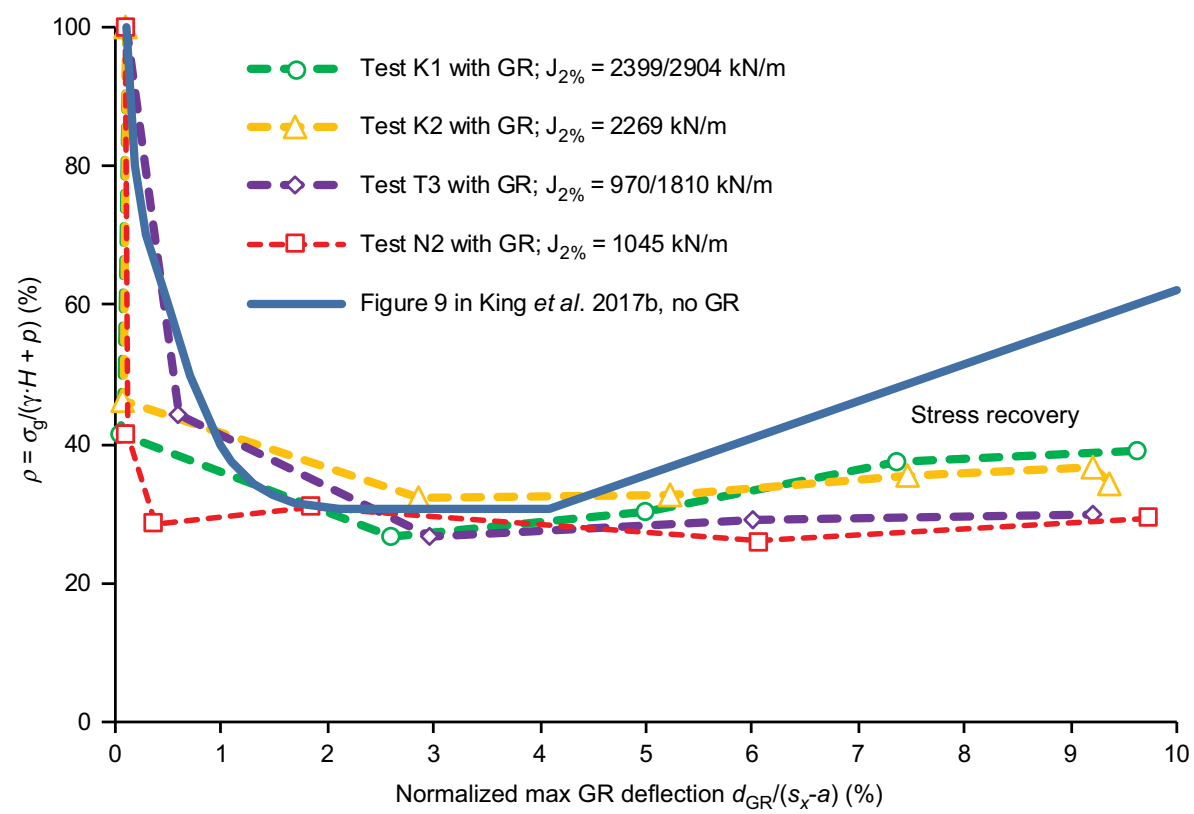

Figure 14. Ground Reaction Curves measured in four experiments reported by Van Eekelen et al. (2012a) compared with the Ground Reaction Curve of King et al. (2017b). Note: GR = geosynthetic reinforcement

arching to maximum arching to ultimate arching corresponds to the change of soil arch shape.

The GRC curves were developed mainly for piled embankments without geosynthetic reinforcement. The influence of the reinforcement was not considered. The authors of this paper believe that GRC curves can also be used for GRPS embankments. However, Rui et al. (2019a) showed that reinforcement stiffness had a large effect on all the phases of the GRC curves. This was confirmed by the experiments of Van Eekelen et al. (2012a) (see Figure 14). In Figure 14, $J_{2 \%}$ is the reinforcement stiffness at $2 \%$ reinforcement strain in the cross-machine direction/machine direction for a loading period of a week, which is in line with the duration of an experiment. Figure 14 compares the GRC curve obtained from the experiments with reinforcement by Van Eekelen et al. (2012a) with the GRC curve by King et al. (2017b) determined for the situation without reinforcement. The figure shows that the stress recovery phase may be less steep or not present when reinforcement is used, indicating that soil arching is more stable for GRPS embankments than for CPS embankments. Shen et al. (2020b) found the same phenomenon in their centrifuge tests.

Figure 15 compares more than 100 measurements taken from numerous field tests and laboratory tests with the reinforcement strains calculated with the Concentric Arches model (Van Eekelen et al. 2013; Van Eekelen et al. 2015) and EBGEO (2010). Figure 15a shows the calculation method adopted in EBGEO (2010) and the earlier CUR226 (2010) guideline, while Figure 15b shows the Concentric Arches model adopted in Van Eekelen and Brugman (2016). This figure shows that the reinforcement strain calculated by EBGEO (2010) and CUR226 (2010) 


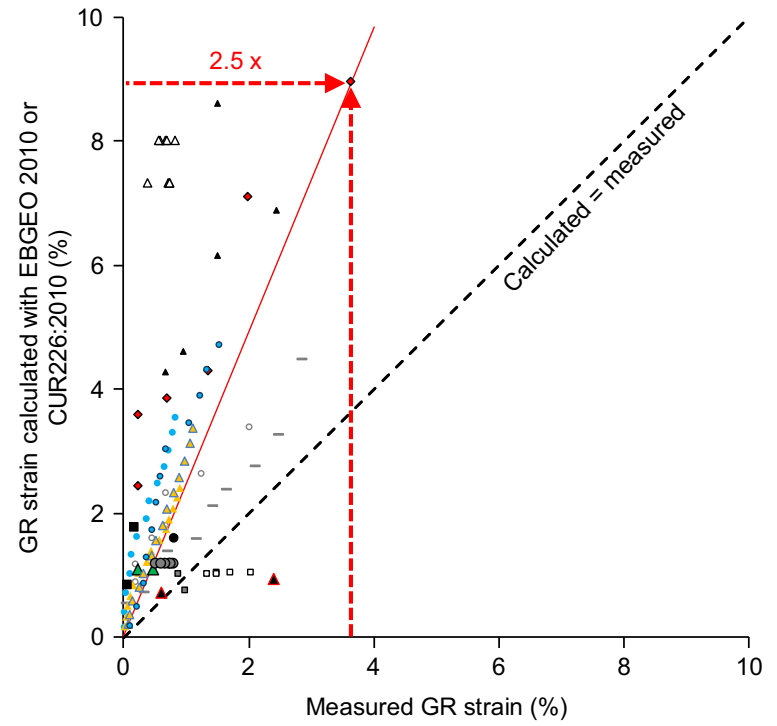

(a)

- Van Eekelen et al. 2012a scaled experiment N1

- Van Eekelen et al. 2012a scaled experiment N3

Zaeske 2001 scaled experiment 7

- Zaeske 2001 scaled experiment 6

- Van Eekelen et al. 2012c field measurements

- Oh and Shin 2007 large scale experiments

- Weihrauch et al. 2013 field measurements

- Almeida et al. 2007 full scale experiment

- - - Measured $=$ calculated

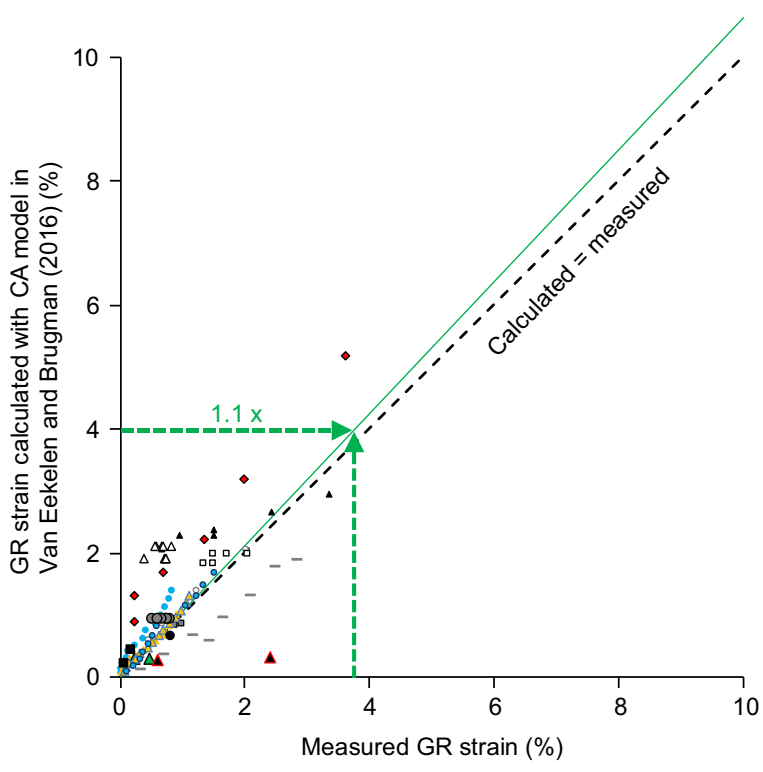

(b)

- Van Eekelen et al. 2012a scaled experiment N2

- Zaeske 2001 scaled experiment 5

$\triangle$ Zaeske 2001 scaled experiment 8

$\Delta$ Van Duijnen et al. 2010 field measurements

- Huang et al. 2009 field measurements

- Haring et al. 2008 field measurements

- Vollmert et al. 2007 field measurements

$\Delta$ Briancon and Simon 2012 full scale experiment

Trendline

Figure 15. Measured versus calculated geosynthetic reinforcement tensile strains in field pile-supported embankments and full-scale and reduced-scale laboratory experiments including a trend line through all data (Van Eekelen et al. 2015). Note: CA model - Concentric Arches model of Van Eekelen et al. (2013) and Van Eekelen et al. (2015)

is on average 2.5 times the measured reinforcement strain and that the reinforcement strain calculated by the Concentric Arches model is on average 1.1 times the measured reinforcement strain. In addition, the data points in Figure $15 \mathrm{~b}$ are much closer to the $1: 1$ line than those in Figure 15a. The coefficient of determination in Figure $15 \mathrm{~b}$ is $R^{2}=0.427$, which is better than $R^{2}=0.072$ in Figure 15a. In other words, the calculated reinforcement strain by the Concentric Arches model is a much better match with the measured reinforcement strain on average, which led Van Eekelen and Brugman (2016) to adopt the Concentric Arches model. Girout et al. (2016) and Lehn et al. (2016) found a similar good match between the Concentric Arches model and centrifuge test data.

\subsection{Analytical models for tensile strain in geosynthetic reinforcement}

The widely adopted two-step design approach in design codes de-couples the arching and the load-deflection relationship of the reinforcement. The first calculation step for the arching distributes the load between pile caps and reinforcement + subsoil. The second step for the reinforcement load-deflection relationship calculates the reinforcement tensile force and strain. A proper design should calculate the maximum reinforcement tensile force and strain, which should meet the requirements for the reinforcement tensile strength in the ultimate limit state (ULS) and the reinforcement tensile strain in the serviceability limit state (SLS).

Step 1 uses the soil arching ratio, stress reduction factor or one of the other parameters listed in Table 1 to calculate the applied pressure on the subsoil without reinforcement or reinforcement + subsoil due to the arching. Most models do not consider this ratio or factor to be dependent on the reinforcement deflection. This approach is widely used and considered to be reasonable for the ultimate limit state design of GRPS embankments (King et al. 2017b). However, to evaluate the serviceability of GRPS embankments, the relationship between the arching ratio and the reinforcement deflection may be considered using the ground reaction curve (King et al. 2017b, Figure 13) or the LDC method (Filz et al. 2012, 2019).

Step 2 calculates the reinforcement tensile force or strain by considering the reinforcement strip between adjacent pile caps because most load is attracted towards this strip, as explained in Section 2.1. Past studies have shown that most reinforcement strains are measured in the direction along the strips (Zaeske 2001; Almeida et al. 2007; Van Eekelen and Bezuijen 2013). To calculate the reinforcement tensile force or strain, the net pressure 
between the applied load distribution on the reinforcement and the reaction from the subsoil support should be known. The reaction from the subsoil support may be modelled using springs with a subgrade reaction modulus $k_{s}\left(\mathrm{kN} / \mathrm{m}^{3}\right)$ as stiffness or using a continuum medium subjected to one-dimensional consolidation. As explained in Section 2.1, the pressures on these strips are highest close to the piles but lowest at mid-span when there is no, or limited, subsoil support. This load distribution can be described approximately by parabolic or inversetriangular shapes for no, or limited, subsoil support respectively. With more subsoil support, the load distribution on the reinforcement strip becomes more uniform, as described in Van Eekelen et al. (2015). Han and Gabr (2002) and Zhuang et al. (2020) conducted axisymmetric numerical analyses respectively and also found the lowest pressure in the center between the piles and highest pressure close to the pile caps. Zhuang et al. (2020) simplified this load distribution into an inverted trapezoid. Van Eekelen (2015) and Zhuang et al. (2020) provided the equations for Step 2 calculations. Both Van Eekelen et al. (2012b) and Filz et al. $(2012,2019)$ take into account the subsoil resistance below the entire area between the pile caps. This differs from the approach in EBGEO (2010), which takes into account only the subsoil underneath the reinforcement strips between adjacent pile caps. Both Abusharar et al. (2009) and Pham (2020) take into account the interface friction between the geosynthetic and the surrounding soil in the calculation of the reinforcement deflection and show that this interface friction leads to a limited reduction of the reinforcement deflection: $2 \%$ for low embankments to $5 \%$ for higher embankments. The models used in European design guidelines - Van Eekelen and Brugman (2016), which adopted the model of Van Eekelen et al. (2013), Van Eekelen et al. (2015), EBGEO (2010), which adopted the model of Zaeske (2001), BS8006-1 (BSI 2010), which adopted the model of Jones et al. (1990) and ASIRI (2012), which adopted the step-2 approach of BS8006-1 (BSI 2010) - consider the reinforcement strips in Step 2 and calculate the maximum tensile force at the edges of the pile caps. This result agrees with the numerical results from Han and Gabr (2002), and the measurements presented by Almeida et al. (2007), Van Eekelen and Bezuijen (2013), Van Eekelen et al. (2014), and Bhandari and Han (2018).

Abusharar et al. (2009), Deb (2010), and Lu and Miao (2015) do not consider the reinforcement strips between adjacent pile caps in the calculation of the reinforcement tensile force because their models are axisymmetric. These models all take consolidation of the subsoil into account. Filz et al. (2012, 2019) and McGuire et al. (2020) proposed the load-displacement compatibility (LDC) method, which considers the subsoil, reinforcement, and embankment fill as separate elements. Load and displacement must match at the borders of those elements. This method describes the behavior of the subsoil better than the limit equilibrium models but suffers from the limitation of its axisymmetric assumption to separate B and C. In a next step, the LCD method uses a uniform load distribution on the reinforcement strips resulting in a parabolic-shaped reinforcement - as described by Sloan (2011) and based on the method proposed by Jones et al. (1990) and implemented in BS8006 - to estimate the resulting tension and strain in the reinforcement. In addition, Abusharar et al. (2009), Filz et al. (2012, 2019) and $\mathrm{Lu}$ and Miao (2015) calculate the critical arch height. The advantage of the approach adopted by Lu and Miao (2015) is that they calculate the arching by including the shear stress mobilized in the slip planes in the fill caused by the development of differential settlement between piles (caps) and subsoil at the bottom of the embankment.

Shen et al. (2018) conducted 3D-model tensionedmembrane laboratory tests in which a uniform pressure was applied to the geosynthetic supported by square pile caps in a square pattern. There was no resistance below the geosynthetic. Shen et al. (2018) found that, in these conditions, the tensile strains developed mainly in the geosynthetic strips between each pair of adjacent piles. Larger tensile strains developed at the edges of the pile caps, with the maximum tensile strains at the corners of the square pile caps. Section 3.2.2 discusses the tensile strains that develop at the corners of square pile caps in further detail.

Shen et al. (2018) found that both the solutions proposed by McGuire and Filz (2008) and Van Eekelen et al. (2015) considering tensile force-strain compatibility reasonably estimated the measured maximum tensile forces at the edges of the pile caps. The methods proposed by Smith (2005) and Van Eekelen et al. (2015) gave the best estimate of the measured vertical deflection of the geosynthetic reinforcement at the center of two adjacent piles. Further research is needed to accurately estimate the maximum vertical deflection of the geosynthetic reinforcement at the center between four pile caps.

Fagundes et al. (2017) and Almeida et al. (2020) showed that the maximum reinforcement deflection between four piles is approximately $\sqrt{ } 2=1.41$ times larger than the maximum reinforcement deflection of a reinforcement strip.

McGuire et al. (2020) showed that the use of reinforcement may not be necessary if a thick and strong soil layer overlies the compressible soil. On the other hand, if a weak and compressible soil extends to the ground surface and the area replacement ratio of piles is small, McGuire et al. (2020) stated that differential settlements may be too large for reinforcement to practically provide enough reinforcement to avoid excessive strain or the rupture of the reinforcement. They presented a parametric study using the Load Displacement Compatibility method and show that site conditions, GRPS system geometry, and performance requirements may limit the range of circumstances in which reinforcement is needed for effective and practical settlement reduction. This range may be different, or it may be less of an issue in countries where high-strength geosynthetics (tensile stiffness $J>10,000 \mathrm{kN} / \mathrm{m}$ ) are used more frequently, as reported for a railway in the Netherlands (Van der Stoel et al. 2012) for example. 


\subsection{Subsoil support}

Geosynthetic reinforcement deflection between pile caps due to subsoil compression is unavoidable and necessary for the development of soil arching and reinforcement tension in a GRPS embankment. Chen et al. (2008b) and Van Eekelen et al. (2012a) both showed experimentally that, under a constant surcharge load, decreasing subsoil support results in increasing soil arching in a GRPS embankment. Most analytical models do not include this mechanism. The exceptions are Deb (2010), King et al. (2017b), and Filz et al. (2012, 2019). However, Chen et al. (2008b) and Van Eekelen et al. (2012a) have also shown that decreasing subsoil support leads to an increase in the reinforcement tensile forces. Jones et al. (1990) demonstrated that subsoil support reduces the required reinforcement tensile strength. This effect becomes more apparent when pile spacing is large. However, in line with the recommendation made by Jones et al. (1990), BS8006 adopted a conservative assumption and decided not to include the subsoil support that may be present (in other words, it is assumed that the entire load is transferred to the piles). This assumption results in a conservative prediction of the tensile forces generated in the reinforcement.

Later, Han (1999), EBGEO (2010), and Van Eekelen and Brugman (2016) stated that subsoil support may be used in reinforcement design for GRPS embankments, albeit only with caution in the following cases (modified after Han 1999):

- soft soil with undrained shear strength $c_{u}<10 \mathrm{kPa}$

- liquefaction

- lowering of the water table, including temporary drainage activities (for adjacent excavations, for instance)

- dissipation of pore water pressure not due to embankment loading

- sinkholes due to Karstic collapse

- collapsible soil

- municipal solid waste settlement, and

- soil loss due to adjacent excavation and tunneling.

As described in Section 3.2.3, subsoil support in GRPS embankments should be treated differently in short-term and long-term calculations because the situation when an embankment is put into use is different from that at the end of its service life. In many cases, there is no longer any subsoil support at the end of the service life of an embankment.

EBGEO (2010) includes subsoil support in the design but it takes into account only the subsoil underneath the reinforcement strips between adjacent piles. Lodder $e t$ al. (2012) and Van Eekelen et al. (2012b) introduced an increased value for the subgrade reaction modulus to take into account all the subsoil in the entire area between the pile caps. This modification improved the agreement between the calculation model and measurements, which is in line with McGuire et al. (2020).

Sections 2.3 and 3.3 discuss the interaction between subsoil consolidation and soil arching development using the Ground Reaction Curves.

\subsection{Vertical deformations}

Surface settlement calculations are not commonly performed in most countries. Rui et al. (2019b) proposed an analytical method to calculate the deformations at ground surface from the nominal reinforcement deflection (see Section 3.2.3). Filz et al. (2019) provided a method for estimating the uniform surface settlement of embankments supported by piles. Numerical methods may also be used for projects with strict settlement requirements.

Several other researchers have proposed methods for analytically estimating settlement at the base of an embankment. Filz et al. (2012, 2019) considered onedimensional consolidation of the soil between piles under reduced vertical stresses due to soil arching using the modified Terzaghi method. King et al. (2017b) used the ground reaction curve (GRC) and one-dimensional consolidation of the soil between piles in their calculation of the settlement at the base of the embankment (see Sections 2.3 and 3.3). Shen et al. (2020a) proposed analytical methods based on pile group and stress distribution to calculate the settlement of the embankment supported by end-bearing or floating piles (see Section 3.6). Rui et al. (2019b) proposed a simplified method to estimate the vertical stress-settlement responses of pile-supported embankments on soft soils, in which the stress concentration ratio depends on the relative settlement between piles and soil.

\subsection{Lateral deformation and pile bending moment}

More and more countries examine lateral deformation in soft soil and pile bending moment using numerical methods and design the piles accordingly. Field monitoring (Gartung et al. 1996) and numerical analyses (Huang et al. 2005; Zheng et al. 2019) have shown that piles or pile caps under embankments are subjected to lateral movement and bending moment. This is particularly true for piles under the embankment slopes, or when there is horizontal ground displacement during specific construction stages. Lateral movement and the bending moment of piles should be considered because they are important to meet the deformation requirements and the dimensioning of the steel reinforcement in the pile or to check the bending capacity of the piles. The amount of steel reinforcement in concrete piles affects their cost and production, and therefore the overall feasibility of pile-supported embankments. The use of geosynthetic reinforcement is expected to reduce lateral deformation and pile bending moment because the reinforcement carries lateral thrust from embankment fill.

Numerical analysis may also be used to determine horizontal deformation in the pile-supported embankment due to construction activities in the vicinity of the embankment, or to determine horizontal deformations that may affect nearby existing structures.

\subsection{Stability}

The global stability of pile-supported embankments has been increasingly researched and considered in design. Zheng et al. (2019) reported on the failure of rigid 
pile-supported embankments due to global instability. Han et al. (2005) and Navin (2005) found that deep mixed column walls under embankments can fail under shear, bending and rotation depending on the strength of the column walls. The limit equilibrium method (an example of which is the Bishop method) overestimates the factor of safety for global stability failure, especially when the column walls fail due to bending or rotation. Zheng et al. (2019) numerically investigated the progressive failure of rigid piles under embankments and found that bending failure was the dominant failure mode. Chai et al. (2017) proposed a simplified method to estimate the maximum tensile stress in deep mixed columns subjected to bending under an embankment. When the maximum tensile stress is higher than the tensile strength of the column, the column will crack or fail.

\subsection{Lateral spreading}

The British Standard BS8006 (BSI 2010), EBGEO (2010), Van Eekelen and Brugman (2016), and the FHWA design guideline (Schaefer et al. 2017) all provide a detailed procedure that considers the lateral spreading of side slopes and results in the additional tensile strength required to resist lateral spreading alongside the tensile strength required to resist vertical loading. Shen et al. (2020b), on the basis of centrifuge tests of GRPS embankments with side slopes, found that this approach was reasonable. Fahmy $(2008,2019)$ presented laboratory experiments and numerical work on the lateral spreading mechanism. He found that conventional analytical methods to determine the spreading forces overestimate the resulting reinforcement tensile force, especially for high embankments, as these methods ignore the effect of the embankment slope and the subsoil stiffness. EBGEO (2010) adopted Fahmy's modified method, which takes these effects into account and gives a lower tensile force in the reinforcement due to spreading.

A few case studies found rotation of pile caps and bending failure of piles, both of which indicate lateral forces on piles. Alexiew and Gartung (1999) observed the rotation of pile caps in their field monitoring in a geogrid-reinforced piled embankment. Huang et al. (2005) numerically modeled this embankment and found bending moments in piles, especially those located away from the center of the embankment.

\subsection{Long-term design}

Since the subsoil between piles deforms and consolidates with time, soil arching is mobilized with time as well. Table 3 distinguishes between full and partial arching as a result of the height of the embankment. In addition, full and partial arching mobilization depends on time. Arching starts to develop immediately after the placement of the fill begins, and this process can continue for several weeks or months until the subsoil effectively stops consolidating and the reinforcement reaches its final deflection. Huang et al. (2009) simulated a constructed GRPS embankment in Finland that took approximately 11 months to complete settlement, while Van Eekelen et al. (2020) showed that this process lasted approximately 1 year at the Woerden embankment in the Netherlands. This process can be accelerated by the application of vertical drains, as shown by Liu and Rowe (2015), or by placing relatively soft, peaty soil between the pile caps, below the reinforcement, as in the case of a $14 \mathrm{~km}$-long GRPS embankment in the Netherlands (Haring et al. 2008).

As described in Section 3.2.3, the in-service geosynthetic reinforcement tensile strain should be calculated as the difference between the average SLS strain immediately after construction and the average SLS strain at the end of the service life. These two situations involve different geosynthetic behaviors, surcharge loads, and subsoil support. The stiffness and strength of the geosynthetic depend on the strain and load duration. The reinforcement tensile stiffness at the end of construction is therefore higher than the tensile stiffness at the end of service life. In addition to the reinforcement creep (i.e. deformation increasing with time under a constant tensile force), reinforcement relaxation (i.e. tensile force decreasing with time under a constant deformation) may play a role during service life. After the installation of the reinforcement, subsoil support decreases with time as a result of consolidation.

During the service life of embankments, they may be subjected to cyclic loading, especially in highway and railway applications. Section 2.5.3 describes the influence of cyclic loading, which can both increase and decrease soil arching. During the rest periods (i.e. between periods of cyclic loading), soil arching may recover if the embankment is high enough.

\subsection{Numerical analyses}

Most designers conduct Finite Element Method (FEM) or Finite Difference Method (FDM) numerical analyses to determine deformation, global stability, transverse shear forces in the piles, and pile bending moments, as well as to analyze complex geometries or complex construction processes and the consequences of horizontal traffic loads. Before any numerical analysis, the numerical model - including, but not limited to model size, mesh size, and material constitutive models and properties - should be validated against field and/or laboratory data. The discrete element method (DEM) has been used by researchers (such as Han et al. 2012) to investigate the mechanisms or interactions between embankment fill, geosynthetic reinforcement, and pile caps. This method is excellent for modeling particle interaction (such as soil arching and soil-geosynthetic interaction) but it requires significant computation time; it is therefore not feasible for actual design at the present time. In current design practice, it is common to model the GRPS embankment two-dimensionally. However, it should be realized that $2 \mathrm{D}$ plane-strain calculations of a piled embankment may model deep mixed column walls or beams on piles, while axisymmetric modeling of a piled embankment with a unit cell concept may be appropriate only for a location close to the centerline of the embankment. However, for adequate design in complex situations, or for research purposes, 3D modeling is preferred or necessary for understanding global behavior (e.g. global 
distribution of settlement, reinforcement tensile force, and pile lateral movement) and local behavior (e.g. differential settlement between piles and maximum tensile force in geosynthetic reinforcement) at the same time.

\section{FUTURE RESEARCH}

During the First International Workshop on Geosynthetic-Reinforced Pile-Supported Embankments in Shanghai, China, in June 2017, the following topics were identified for future research:

- influence of shape and rigidity of a trapdoor on the soil arching results

- localized versus uniform loading on soil arching

- cyclic loading on soil arching

- seismic effects on GRPS embankments

- long-term performance of GRPS embankments (e.g. geosynthetic reinforcement creep and relaxation, stress recovery), and

- GRPS embankments with floating piles and/or complex construction processes.

As discussed earlier, the effect of water on soil arching and the performance of GRPS embankments should be researched. This paper did not discuss the issues related to earthquake loading. This is a topic that may require more study in the future.

\section{CONCLUDING REMARKS}

This section provides a summary of the principal conclusions from this paper.

\subsection{Load transfer}

Soil arching is the mechanism of load distribution in which the load is attracted towards elements that behave relatively stiffly or move relatively little with respect to their adjacent elements.

The piles in a CPS embankment therefore attract a relatively large proportion of the vertical load and the remaining load is transferred to the subsoil between the piles. The load on this subsoil is distributed approximately uniformly because the deformation of the subsoil is approximately uniform.

In a GRPS embankment, the piles also attract a relatively large part of the load. The remaining part of the load rests on the geosynthetic reinforcement, which deforms with the underlying subsoil, and this remaining load part is distributed as follows.

- A relatively large part of the load is exerted on the reinforcement strips between adjacent piles because these strips have the shortest span between adjacent piles, resulting in the reinforcement strips deflecting less than elsewhere and attracting a relatively higher load.

- The load on a reinforcement strip is not distributed uniformly: more load is exerted at the location closer to the pile cap as a result of the reinforcement deflecting less at this location than in the middle between pile caps.

Soil arching is influenced by many factors. They include, but are not limited to, embankment height, fill properties, differential settlement, geosynthetic properties, subsoil support, pile stiffness, end-bearing condition, pattern, size, shape, and spacing, and surface loading. The development of soil arching with differential settlement can be described with a ground reaction curve.

It is commonly believed that critical height should be considered in design. Critical height depends on several factors but mostly on pile pattern, size, and spacing. Soil arching should not be considered in design when the embankment height is less than $2 / 3$ of the maximum pile cap clear spacing $(H<0.66(s-a))$.

Multiple geosynthetic layers (up to three layers) with small spacing, or none, between the layers, behave as a single layer, with total tensile stiffness and strength being equal to the summed stiffnesses and strengths of the individual layers if the embankment height allows the full development of soil arching.

Piles should be stiff enough with respect to the surrounding soil to ensure soil arching. Most current soil arching models were developed based on rigid supports or end-bearing piles. The authors of the paper believe that soil arching may be taken into account if the pile-soil modulus ratio is 50 to 100 or larger.

Floating (frictional) piles are rarely used, with the exception of a limited number of countries.

$3 \mathrm{D}$ soil arching is more critical than $2 \mathrm{D}$ soil arching because the pressure on the geosynthetic reinforcement between the piles is lower than between beams of the same width and spacing.

Cohesion should not be considered for soil arching in design.

Surface static and cyclic loading affect the development of soil arching. Cyclic loading has more effect than static loading. Higher embankments and geosynthetic reinforcement reduce the degradation of soil arching due to cyclic loading and increase the safety of the constructed embankments.

Cyclic loading increases the geosynthetic tensile force but the effect of the cyclic loading on the rate of the tensile force increase decreases with time. For a sufficiently high embankment with proper geosynthetic reinforcement above the piles, the combined soil arching and tensioned membrane effect may be enhanced by cyclic loading.

Soil arching recovers after cyclic loading is stopped or paused if the embankment is sufficiently high to allow stable soil arching.

\subsection{Subsoil support}

Subsoil support has a significant effect on the required tensile strength of the geosynthetic reinforcement. Subsoil support for short-term design or for the situation immediately after construction should be considered, but subsoil support for long-term design may also be used except in the conditions identified in Section 3.2: Deformation. 
Settlement calculations are not commonly done in most countries. For projects with strict settlement requirements, numerical methods may be used for the design.

Geosynthetic strain limit requirements are frequently required for construction and during service life, with a typical strain range of $2-6 \%$. For the design of the geosynthetic reinforcement, numerical methods can be used along with validated analytical methods for the reinforcement design.

\subsection{Stability}

It is important to consider the stability of GRPS embankments in design. A few case studies found rotation of pile caps and bending failure of piles, which indicated lateral forces on piles. In most countries, engineers use numerical analysis to calculate pile bending moment and pile shear forces if required in a project. Most jurisdictions do not require a check on stability using limit equilibrium (LE) methods; however, numerical methods have been increasingly used for this purpose.

\section{ACKNOWLEDGEMENTS}

This state-of-the-art paper was developed based on the outcomes from the First International Workshop on Geosynthetic-Reinforced Pile-Supported Embankments held in Shanghai, China from 14-16 June 2017, the technical papers in this special issue on GeosyntheticReinforced Pile-Supported Embankments, the research results from others in the literature, and the authors' personal knowledge. The experts invited to the workshop in 2017 were: C. Xu (chair), R. Chen, G. Zheng, J. Zheng, S. Liu, Y. Zhuang, X. Bian, F. Xiao, and R. Rui from China; J. Han (chair) and J. Collin from USA; S.J.M. Van Eekelen (chair) from Netherlands; S. Liyanapathirana and L. King from Australia; Márcio de Souza Soares de Almeida and M.C.F. Almeida from Brazil; M. Blanc from France; S.J. Hao from Malaysia; and Reshma B. from India. Approximately 70 people participated in this workshop. This workshop was organized by Tongji University, funded by the Ministry of China Changjiang Scholars fund and the National Natural Science Foundation of China (No. 51478349), and sponsored by the industrial partners: Maccafferi, Tencate, Tianan Road Engineering Materials, Hock Technology, and NETE. The authors appreciate the contributions from all the authors to this special issue. The authors also would like to thank Professor R.J. Bathurst, the editor of Geosynthetics International, for giving us the opportunity to act as guest editors for this special issue.

\section{NOTATION}

Basic SI units are given in parentheses.

$A$ load part transferred directly to the pile ('arching $A$ ' in this paper) expressed in $\mathrm{N} /$ pile $=\mathrm{N} /$ unit cell $(\mathrm{N} /$ pile $)$

$a$ width of a square pile cap (m) $a_{\text {eq }}$ equivalent width of a circular pile cap (m)

$A \% \quad$ see $E$ below, see Table $1(\mathrm{~N} / \mathrm{N})$

$A_{\mathrm{g}}$ area of the geosynthetic between the pile caps, for a rectangular pile pattern: $A_{\mathrm{g}}=\left(s_{x} \cdot s_{y}-A_{\mathrm{p}}\right)\left(\mathrm{m}^{2}\right)$

$A_{\mathrm{i}} \quad$ area of influence of one pile unit, for a rectangular pile pattern: $A_{\mathrm{i}}=s_{x} \cdot s_{y}\left(\mathrm{~m}^{2}\right)$

$A_{\mathrm{p}}$ area of a pile cap $\left(\mathrm{m}^{2}\right)$

$A_{\text {strip }}$ area of a reinforcement strip between adjacent pile $\left(\mathrm{m}^{2}\right)$

$B$ load part that passes through the geosynthetic reinforcement to the pile, expressed in $\mathrm{N} /$ pile $=\mathrm{N} /$ unit cell $(\mathrm{N} /$ pile $)$

$C$ load part that is carried by the soft soil between the piles (this soft soil foundation is called 'subsoil' in this paper) expressed in N/pile $=\mathrm{N} /$ unit cell $(\mathrm{N} /$ pile $)$

$c_{\mathrm{u}} \quad$ undrained shear strength $(\mathrm{Pa})$

$D$ normalized displacement (see Figure 13): vertical deflection/net pile spacing (dimensionless)

$d$ diameter of a circular pile (cap) (m)

$d_{\text {eq }}$ equivalent diameter of a square pile cap (m)

$E$ pile efficacy or pile efficiency. See Tables 1 and 2: these tables give different definitions (dimensionless)

$E_{\text {crown }}$ Hewlett and Randolph's (1988) pile efficacy, as defined in Table 1, calculated assuming equilibrium for the crown element (Table 3f, left hand side) (N/N)

$E_{\text {pile cap }}$ Hewlett and Randolph's (1988) pile efficacy, as defined in Table 1, calculated assuming equilibrium at the pile cap (Table $3 \mathrm{f}$, right hand side) $(\mathrm{N} / \mathrm{N})$

$H$ embankment height, (between road surface and pile cap) (m)

$H_{\text {ca }}$ critical arching height according to Lai et al. 2018, see Table 3 (e.g. $0.8 \cdot\left(s_{x}-a\right)$ ) (m)

$H_{\text {co }} \quad$ critical overlying filling height according to Lai et al. 2018, see Table 3 (e.g. 3.0·a) (m)

$H_{\text {crit }}$ critical height, see Table 3 (m)

$H_{\text {min }}$ minimum embankment height (m), see Table 4

$J\left(J_{x}, J_{y}\right)$ tensile stiffness of the geosynthetic reinforcement (GR stiffness) $(\mathrm{N} / \mathrm{m})$

$J_{2 \%} \quad$ Tensile stiffness of the geosynthetic reinforcement at 2\% reinforcement strain $(\mathrm{N} / \mathrm{m})$

$K \quad$ lateral earth pressure coefficient (ratio between horizontal and vertical pressure) (dimensionless)

$k$ characteristic value of a parameter (subscript).

$k_{s} \quad$ subgrade reaction modulus $\left(\mathrm{N} / \mathrm{m}^{3}\right)$

$k_{p} \quad$ stiffness of the piles, defined as $k_{p}=(A+B) /\left(s_{\mathrm{p}} \cdot A_{\mathrm{p}}\right)\left(\mathrm{N} / \mathrm{m}^{3}\right)$

$k_{\mathrm{s}} \quad$ subgrade reaction $\left(\mathrm{N} / \mathrm{m}^{3}\right)$

$N$ number of load cycles (see Figure 9) (dimensionless)

$p \quad$ surcharge load $(\mathrm{Pa})$ 
$p_{0} \quad$ the average pressure on the level of the pile caps and the reinforcement; that is, $\left.\sigma_{0}=p_{0}=(A+B+C) / A_{\mathrm{i}}\right)=\gamma H+p(\mathrm{~Pa})$

$R^{2} \quad$ coefficient of determination (dimensionless) SRR stress reduction ratio:

$\left[(B+C) /\left(s_{x} \cdot s_{y}-A_{\mathrm{p}}\right)\right] /\left[(\gamma \cdot H+p) /\left(s_{x} \cdot s_{y}\right)\right]$ or $\left[C /\left(s_{x} \cdot s_{y}-A_{\mathrm{p}}\right)\right] /\left[(\gamma \cdot H+p) /\left(s_{x} \cdot s_{y}\right)\right]$. It is not recommended to use SRR as this parameter often makes no distinction between a load that is transferred by arching and a load that is transferred through arching and through the GR (dimensionless)

$s^{\prime}$ half the diagonal clear spacing between piles: $s^{\prime}=0.5 \cdot\left(s_{d}-d\right)(\mathrm{m})$

$s_{d}$ the diagonal center-to-center distance between piles $s_{d}=\sqrt{s_{x}^{2}+s_{y}^{2}}(\mathrm{~m})$

$s_{G R}$ maximum deflection of reinforcement (m)

$s_{\mathrm{p}} \quad$ settlement of the pile cap (m)

$s_{x}, s_{y} \quad$ center-to-center pile distance parallel to the $x$-axis or parallel to the $y$-axis. (m)

$\kappa$ reduction factor to reduce arching due to cyclic loading according to Heitz (2006) (dimensionless)

$\gamma \quad$ fill unit weight $\left(\mathrm{N} / \mathrm{m}^{3}\right)$

$\rho$ soil arching ratio, see Table 2 (dimensionless)

$\sigma_{\mathrm{c}}$ amplitude of the vertical surcharge load on ground surface in the cyclic tests of Heitz (2006) (Pa)

$\sigma_{\mathrm{g}} \quad$ pressure on the reinforcement between the pile caps $(\mathrm{Pa})$

$\sigma_{\mathrm{m}} \quad$ average vertical surcharge load on ground surface in the cyclic tests of Heitz (2006) $(\mathrm{Pa})$

$\sigma_{\mathrm{s}} \quad \sigma_{\mathrm{s}}=C / A_{\mathrm{g}}(\mathrm{Pa})$

$\varphi^{\prime} \quad$ internal friction angle under effective stress conditions (degrees)

$\varphi_{\mathrm{r}}^{\prime} \quad$ critical state value of the internal friction angle under effective stress conditions (degrees)

$\varphi_{\mathrm{p}}^{\prime} \quad$ peak value of the internal friction angle under effective stress conditions (degrees)

$\varphi_{\mathrm{r}, \mathrm{k}}^{\prime} \quad$ characteristic (k) value of the critical state or residual (r) internal friction angle (degrees)

\section{ABBREVIATIONS}

CA model Concentric Arches model of Van Eekelen et al. (2013), Van Eekelen et al. (2015)

CPS embankment conventional piled-supported embankment (without geosynthetic reinforcement)

CPT cone Penetration Test

CUR Dutch institute until 2018, which made and published civil engineering design guidelines. Their guidelines are now published by CROW, Netherlands, and/or CRC Press.
DEM discrete element method

FDM finite difference method

FEM finite element method

GR geosynthetic reinforcement

GRC ground reaction curve (see Figures 13 and 14)

GRPS geosynthetic-reinforced pile-supported (embankment)

LDC load-displacement compatibility method of Filz et al. (2012, 2019) and McGuire et al. (2020)

LE limit equilibrium

PET polyester

PP polypropylene

PS pile-supported

PVA polyvinyl alcohol

\section{REFERENCES}

Abusharar, S. W., Zheng, J. J., Chen, B. G. \& Yin, J. H. (2009). A simplified method for analysis of a piled embankment reinforced with geosynthetics. Geotextiles and Geomembranes, 27, No. 1, 39-52.

Alexiew, D. \& Gartung, E. (1999). Geogrid reinforced railway embankment on piles performance monitoring 1994-1998. Proceedings of I Simpósio Sul-Americano de Geossintéticos '99, Rio de Janeiro, (the 1st South American Symposium on Geosynthetics), Brazil, pp. 403-411.

Almeida, M. S. S., Ehrlich, M., Spotti, A. P. \& Marques, M. E. S. (2007). Embankment supported on piles with biaxial geogrids. Geotechnical Engineering, 160, No. GE4, 185-192.

Almeida, M. S. S., Fagundes, D. F., Thorel, L. \& Blanc, M. (2020). Geosynthetic-reinforced pile-embankments: numerical, analytical and centrifuge modelling. Geosynthetics International, Special Issue on Geosynthetic-Reinforced Pile-Supported Embankments https://doi.org/10.1680/jgein.19.00011.

Al-Naddaf, M., Han, J., Jawad, S., Abdulrasool, G. \& Xu, C. (2017). Investigation of stability of soil arching under surface loading using trapdoor model tests. Proceedings of the 19th International Conference on Soil Mechanics and Geotechnical Engineering, Korea, Technical Committee 104, CRC Press, Boca Raton, FL, USA, pp. 889-892.

Al-Naddaf, M., Han, J., Xu, C. \& Rahmaninezhad, S. M. (2019a). Effects of geofoam on vertical stress distribution on buried structures subjected to static and cyclic footing loads. Journal of Pipeline Systems - Engineering and Practice, 10, No. 1, 04018027, $1-12$.

Al-Naddaf, F., Han, J., Xu, C., Jawad, S. \& Abdulrasool, G. (2019b). Experimental investigation of soil arching mobilization and degradation under localized surface loading. Journal of Geotechnical and Geoenvironmental Engineering, 145, No. 12, 04019114-1-04019114-17.

Aqoub, K., Mohamed, M. \& Sheehan, T. (2020). Analysis of unreinforced and reinforced shallow piled embankments under cyclic loading. Geosynthetics International, Special Issue on Geosynthetic-Reinforced Pile-Supported Embankments, https://doi. org/10.1680/jgein.19.00010.

Ariyarathne, P. \& Liyanapathirana, D. S. (2014). Review of existing design methods for geosynthetic-reinforced pile-supported embankments. Soils and Foundations, 55, No. 1, 17-34.

ASCE (American Society of Civil Engineers) (1997). Ground improvement, ground reinforcement, ground treatment developments 1987-1997. Sessions of Geo-Logan '97 Conference, Logan, Utah, Schaefer, V. R., Abramson, L. W., Drumheller, J. C. \& Sharp, K. D., Editors, Geotechnical Special Publication No. 69, Reston, VA, USA, p. 616. 
ASIRI (2012). Recommandations pour la conception, le dimensionnement, l'exécution et le contrôle de l'amélioration des sols de fondation par inclusions rigides, ASIRI. Presses de l'école nationale des Ponts et Chaussées, Paris, France (in French). Also available in English: Recommendations for the design, construction and control of rigid inclusions ground improvements (2013). Paris : Presses des ponts, 2013.

Bathurst, R. J., Allen, T. M. \& Walters, D. L. (2002). Short-term strain and deformation behavior of geosynthetic walls at working stress conditions. Geosynthetics International, 9, No. 5-6, 451-482.

Bhandari, A. (2010). Micromechanical Analysis of Geosynthetic-Soil Interaction Under Cyclic Loading. Ph.D. dissertation, the University of Kansas, Lawrence, KS, USA.

Bhandari, A. \& Han, J. (2018). Two-dimensional physical modelling of soil displacements above trapdoors. Geotechnical Research, 5, No. 2, pp. 68-80, https://doi.org/10.1680/jgere.18.00002, Paper 18.00002 .

Bhasi, A. \& Rajagopal, K. (2015). Numerical study of basal reinforced embankments supported on floating/end bearing piles considering pile-soil interaction. Geotextiles and Geomembranes, 43, No. 6, 524-536.

Bian, X., Duan, X., Chen, R. P. \& Chen, Y. M. (2017). Dynamic stress response of geosynthetic-reinforced pile-supported embankment under train moving load. Presentation at the First International Workshop on Geosynthetic-Reinforced Pile-Supported Embankments, Shanghai, China.

Blanc, M., Thorel, L., Girout, R. \& Almeida, M. S. S. (2014). Geosynthetic reinforcement of a granular load transfer platform above rigid inclusions: comparison between centrifuge testing and analytical modelling. Geosynthetics International, 21, No. 1, $37-52$.

Briançon, L. \& Simon, B. (2012). Performance of pile-supported embankment over soft soil: full-scale experiment. Journal of Geotechnical and Geoenvironmental Engineering, 138, No. 4, 551-561.

Britton, E. J. \& Naughton, P. J. (2010). An experimental study to determine the location of the critical height in piled embankments. Proceedings of the 9th International Conference on Geosynthetics (ICG9), Brazilian Chapter of the International Geosynthetics Society, Brazil, pp. 1961-1964.

BSI (1995). BS8006: Code of Practice for Strengthened/Reinforced Soils and Other Fills. British Standards Institution, London, UK.

BSI (2010). BS8006-1: Code of practice for strengthened/reinforced soils and other fills. British Standards Institution, London, UK.

Cain, W. (1916). Earth pressure, retaining walls and bins. John Wiley and Sons. Inc., New York, NY, USA.

Cao, W. Z., Zheng, J. J., Zhang, J. \& Zhang, R. J. (2016). Field test of geogrid-reinforced and floating pile-supported embankment. Geosynthetics International, 23, No. 5, 348-361.

Carlsson, B. (1987). Reinforced Soil, Principles for Calculation, Terratema AB, Linköping (in Swedish).

Chai, J. C., Shrestha, S., Hino, T. \& Uchikoshi, T. (2017). Predicting bending failure of CDM columns under embankment loading. Computers and Geotechnics, 91, 169-178, http://dx.doi.org/10.1016/ j.compgeo.2017.07.015.

Chen, R. P., Chen, Y. M., Han, J. \& Xu, Z. Z. (2008a). A theoretical solution for pile-supported embankments on soft soil. Canadian Geotechnical Journal, 45, No. 5, 611-623.

Chen, Y. M., Cao, W. P. \& Chen, R. P. (2008b). An experimental investigation of soil arching within basal reinforced and unreinforced piled embankments. Geotextiles and Geomembranes, 26, No. 2, 164-174

Chen, R. P., Xu, Z. Z., Chen, Y. M., Ling, D. S. \& Zhu, B. (2010). Field tests on pile-supported embankments over soft ground. Journal of Geotechnical and Geoenvironmental Engineering, 136, No. 6, 777-785.

Chen, R. P., Wang, Y. W., Ye, X. W., Bian, X. C. \& Dong, X. P. (2016). Tensile force of geogrids embedded in pile-supported reinforced embankment: a full-scale experimental study. Geotextiles and Geomembranes, 44, No. 2, 157-169.
Chew, S. H., Phoon, H. L., Le Hello, B. \& Villard, P. (2006). Geosynthetic reinforced piled embankment - large-scale model tests and numerical modelling. 8th International conference on geosynthetics, Yokohama, Japan, Kuwano, J. \& Koseki, J., Editors, Millpress, Rotterdam, the Netherlands, vol. 3, pp. 901-904.

Chow, L. C., Han, J. \& Reuter, G. R. (2020). Field monitoring of negative skin friction on rigid inclusion columns under embankments. Proceedings GeoCongress 2020, ASCE, Reston, VA, USA

Costa, Y. D., Zornberg, J. G. \& Bueno, B. S. \& Costa, C. (2009). Failure Mechanisms in Sand Over a Deep Active Trapdoor, J. Geotech. Geoenviron. Eng., 135, No. 11, 1741-1753.

Da Silva, T. S., Elshafie, M. Z. E. B. \& Madabhushi, G. S. P. (2016). Centrifuge modelling of arching in granular soils. Institut Francais des Sciences et Technologies des Transports, de l'Amenagement et des Reseaux (IFSTTAR), Nantes, France, pp. 301-306.

Deb, K. (2010). A mathematical model to study the soil arching effect in stone column-supported embankment resting on soft foundation soil. Applied Mathematical Modelling, 34, No. 12 , 3871-3883.

Deb, K. \& Mohapatra, S. R. (2013). Analysis of stone column-supported geosynthetic-reinforced embankments, Applied Mathematical Modelling, 37, No. 5, 2943-2960, 1 March 2013.

Demerdash, M. A. (1996). An Experimental Study of Piled Embankments Incorporating Geosynthetic Basal Reinforcement. PhD Thesis, Newcastle University, Newcastle upon Tyne, UK.

EBGEO (2010). Empfehlungen für den Entwurf und die Berechnung von Erdkörpern mit Bewehrungen aus Geokunststoffen - EBGEO, German Geotechnical Society, Berlin, Germany (in German).

Ellis, E. \& Aslam, R. (2009a). Arching in piled embankments. Comparison of centrifuge tests and predictive methods, part 1 of 2. Ground Engineering, pp. 34-38.

Ellis, E. \& Aslam, R. (2009b). Arching in piled embankments. Comparison of centrifuge tests and predictive methods, part 2 of 2. Ground Engineering, pp. 28-31.

Eskișar, T., Otani, J. \& Hironaka, J. (2012). Visualization of soil arching on reinforced embankment with rigid pile foundation using X-ray CT. Geotextiles and Geomembranes, 32, 44-54.

Fagundes, D. F., Almeida, M. S. S., Thorel, L. \& Blanc, M. (2017). Load transfer mechanism and deformation of reinforced piled embankments. Geotextiles and Geomembranes, 45, No. 2, $1-10$.

Fahmy, G. S. (2008). Lateral Spreading in Basal Reinforced Embankments Supported by Pile-Like Elements. $\mathrm{PhD}$ thesis, Universität Kassel, Schriftenreihe Geotechnik, Heft 20, Germany.

Fahmy, G. S. (2019). Reinforced embankments on soft soil, focus on lateral spreading. In Proceedings of GeoMeast 2018, Giza, Greater Cairo, Egypt. Choudhury, D., et al., Editors, Springer, Cham, Switzerland, pp. 53-61. https://doi.org/10.1007/ 978-3-030-01920-4 5.

Filz, G., Sloan, J., McGuire, M. P., Collin, J. \& Smith, M. (2012). Column-supported embankments: settlement and load transfer. Proceedings of Geotechnical Engineering State of the Art and Practice, ASCE, Reston, VA, USA, pp. 54-77.

Filz, G. M., Sloan, J. A., McGuire, M. P., Smith, M. \& Collin, J. (2019). Settlement and vertical load transfer in column-supported embankments. Journal of Geotechnical and Geoenvironmental Engineering, 145, No. 10, 04019083-1-04019083-15.

Gallant, A. P., Shatnawi, E., Farouz, E. \& Jones, T. (2018). A case study of settlement and load transfer at depth beneath column-supported embankments. Proceedings of IFCEE 2018, ASCE, Reston, VA, USA, https://doi.org/10.1061/ 9780784481592.034.

Gartung, E., Verspohl, J., Alexiew, D. \& Bergmair, F. (1996). Geogrid reinforced railway embankment on piles-monitoring. In Geosynthetics: Application, Design and Construction, De Groot, M. B., Den Hoedt, G. and Termaat, R.J., Editors, Balkema, Rotterdam, the Netherlands, pp. 251-258. 
Giroud, J. P., Bonaparte, R., Beech, J. F. \& Gross, B. A. (1990). Design of soil layer-geosynthetic systems overlying voids. Geotextiles and Geomembranes, 9, No. 1, 11-50.

Girout, R., Blanc, M., Dias, D. \& Thorel, L. (2014). Numerical analysis of a geosynthetic-reinforced piled load transfer platform validation on centrifuge test. Geotextiles and Geomembranes, 42, No. 5, 525-539.

Girout, R., Blanc, M., Thorel, L., Fagundes, D. F. \& Almeida, M. S. S. (2016). Arching and deformation in a piled embankment: centrifuge tests compared to analytical calculations. Journal of Geotechnical and Geoenvironmental Engineering, 142, No. 12, https://doi.org/10.1061/(ASCE)GT.1943-5606.0001557.

Halvordson, K. A., Plaut, R. H. \& Filz, G. M. (2010). Analysis of geosynthetic reinforcement in pile-supported embankments. Part II: 3D cable-net model. Geosynthetics International, 17, No. $2,68-76$.

Han, J. (1999). Design and construction of embankments on geosynthetic reinforced platforms supported by piles. Invited Speaker, Proceedings ASCE/PaDOT Geotechnical Seminar, Hershey, PA, USA. ASCE, Reston, VA, USA, pp. 14-16.

Han, J. (2015). Principles and Practice of Ground Improvement, John Wiley \& Sons, Hoboken, NJ, USA, 432p.

Han, J. \& Gabr, M. A. (2002). Numerical analysis of geosyntheticreinforced and pile-supported earth platforms over soft soil. Journal of Geotechnical and Geoenvironmental Engineering, 128, No. 1, 44-53.

Han, J., Parsons, R. J., Sheth, A. R. \& Huang, J. (2005). Factors of safety against deep-seated failure of embankments over deep mixed columns. Proceedings of the Deep Mixing 2005 Conference, May 23-25, 2005, Swedish Geotechnical Institute, Stockholm, Sweden, vol. 1.2, pp. 231-236.

Han, J., Oztoprak, S., Parsons, R. L. \& Huang, J. (2007). Numerical analysis of foundation columns to support widening of embankments. Computers and Geotechnics, 34, No. 6, 435-448.

Han, J., Bhandari, A. \& Wang, F. (2012). DEM Analysis of stresses and deformations of geogrid-reinforced embankments over piles. International Journal of Geomechanics, 12, No. 4, 340-350.

Han, J., Wang, F., Al-Naddaf, M. \& Xu, C. (2017). Progressive development of soil arching with displacement. ASCE International Journal of Geomechanics, 17, No. 12, 04017112-1-04017112-12.

Han, J., Wang, F., Al-Naddaf, M. \& Xu, C. (2019). Progressive development of soil arching with displacement: closure. ASCE International Journal of Geomechanics, 19, No. 3, 07018022-1-07018022-3.

Handy, R. L. (1985). The Arch in Soil Arching. Journal of Geotechnical Engineering, 3, No. 3, 19547.

Haring, W., Profittlich, M. \& Hangen, H. (2008). Reconstruction of the national road N210 Bergambacht to Krimpen a.d. IJssel, NL: design approach, construction experiences and measurement results. Proceedings of the 4th European Geosynthetics Conference, (Eurogeo 4), IGS, Edinburgh, UK, Paper number 259.

Heitz, C. (2006). Bodengewölbe Unter Ruhender und Nichtruhender Belastung bei Berücksichtigung von Bewehrungseinlagen aus Geogittern. PhD Thesis, Schriftenreihe Geotechnik, Uni Kassel, Kassel, Germany (in German).

Hewlett, W. J. \& Randolph, M. F. (1988). Analysis of piled embankments. Ground Engineering, 21, No. 3, 12-18.

Holtz, R. D. \& Massarsch, K. R. (1976). Improvement of the stability of an embankment by piling and reinforced earth. Proceedings of the 6th European Conference on Soil Mechanics and Foundation Engineering, Vienna, Austria. vol. 1.2, pp. 473-478.

Hong, W. P., Lee, J. \& Hong, S. (2014). Full-scale tests on embankments founded on piled beams. Journal of Geotechnical and Geoenvironmental Engineering, 140, No. 12, https://doi.org/ 10.1061/(ASCE)GT.1943-5606.0001145.

Huang, J., Han, J. \& Collin, J. G. (2005). Geogrid-reinforced pile-supported railway embankments - three dimensional numerical analysis. Journal of Transportation Research Board, 1936, No. 1, 221-229.
Huang, J., Han, J. \& Oztoprak, S. (2009). Coupled mechanical and hydraulic modeling of geosynthetic-reinforced column-supported embankments. Journal of Geotechnical and Geoenvironmental Engineering, 135, No. 8, 1011-1021.

Iglesia, G. R. (1991). Trapdoor Experiments on the Centrifuge: A Study of Arching in Geomaterials and Similitude in Geotechnical Models. $\mathrm{Ph} . \mathrm{D}$. thesis, Dept. of Civil Engineering, MIT, Cambridge, MA, USA.

Iglesia, G. R., Einstein, H. H. \& Whitman, R. V. (1999). Determination of vertical loading on underground structures based on an arching evolution concept. Geo-Engineering for Underground Facilities, Fernandez, G. and Bauer, R. A., Editors, ASCE, Reston, VA, USA, pp. 495-506.

Iglesia, G. R., Einstein, H. H. \& Whitman, R. V. (2014). Investigation of soil arching with centrifuge tests. Journal of Geotechnical and Geoenvironmental Engineering, 140, No. 2, pp. 04013005-1-13.

Jones, C. J. F. P., Lawson, C. R. \& Ayres, D. J. (1990). Geotextile Reinforced Piled Embankments, Geotextiles, Geomembranes and Related Products, den Hoedt, G., Editor, Balkema, Rotterdam, the Netherlands, pp. 155-160.

Jones, B. M., Plaut, R. H. \& Filz, G. M. (2010). Analysis of geosynthetic reinforcement in pile-supported embankments. Part I: 3D plate model. Geosynthetics International, 17, No. 2, $59-67$.

Kempfert, H. G., Göbel, C., Alexiew, D. \& Heitz, C. (2004). German recommendations for reinforced embankments on pile-similar elements. Proceedings of the 3rd European Geosynthetics Congress (Eurogeo 3), Munich, Germany, pp. 279-284.

Kempton, G., Russell, D., Pierpoint, N. D. \& Jones, C. J. F. P. (1998). Two- and three-dimensional numerical analysis of the performance of piled embankments. In Proceedings of the 6th International Conference on Geosynthetics, Atlanta, GA, USA, Rowe R. K., Editor, Industrial Fabrics Association International, St. Paul, MN, USA, pp. 767-772.

Keverling Buisman, A. S. (1937). Letter to: 'de Heer Hoofdingenieur van Provincialen Waterstaat van Zuid Holland', dd 15 maart 1937, archive Deltares, Delft, Netherlands, dossier CO-60(0).

Khansari, A. \& Vollmert, L., (2020). Load transfer and deformation of geogrid-reinforced piled embankments: field measurement. Geosynthetics International, Special Issue on GeosyntheticReinforced Pile-Supported Embankments, https://doi.org/10.1680/ jgein.19.00002.

King, D. J., Bouazza, A., Gniel, J. R., Rowe, R. K. \& Bui, H. H. (2017a). Load-transfer platform behaviour in embankments supported on semi-rigid columns: implications of the ground reaction curve. Canadian Geotechnical Journal, 54, No. 8, 1158-1175, https://doi.org/10.1139/cgj-2016-0406.

King, D. J., Bouazza, A., Gniel, J. R., Rowe, R. K. \& Bui, H. H. (2017b). Serviceability design for geosynthetic reinforced column supported embankments. Geotextiles and Geomembranes, 45, No. 4, 261-279

Lai, H. J., Zheng, J. J., Zhang, J., Zhang, R. J. \& Cui, L. (2014). DEM Analysis of 'soil'-arching within geogrid-reinforced and unreinforced pile-supported embankments. Computers and Geotechnics, 61, 13-23.

Lai, H. J., Zheng, J. J., Zhang, R. J. \& Cui, M. J. (2018). Classification and characteristics of soil arching structures in pile-supported embankments. Computers and Geotechnics, 98, 153-171.

Lawson, C. R. (2000). Serviceability limits for low-height reinforced piled embankments. Proceedings of the ISRM International Symposium, Melbourne, Australia. International Society for Rock Mechanics and Rock Engineering.

Lawson, C. R. (2012). Role of modelling in the development of design methods for basal reinforced piled embankments. Proceedings of EuroFuge, Delft, Netherlands.

Le Hello, B. \& Villard, P. (2009). Embankments reinforced by piles and geosynthetics - numerical and experimental studies with the transfer of load on the soil embankment. Engineering Geology, 106, No. 1-2, 78-91.

Lee, T., Lee, S. H., Lee, I. W. \& Jung, Y. H. (2020). Quantitative performance evaluation of GRPE: a full-scale modeling approach. 
Geosynthetics International, Special Issue on GeosyntheticReinforced Pile-Supported Embankments, https://doi.org/10.1680/ jgein.19.00017.

Lehn, J., Moormann, C. \& Aschrafi, J. (2016). Numerical investigations on the load distribution over the geogrid of a basal reinforced piled embankment under cyclic loading. Advances in transportation geotechnics 3. The 3rd International Conference on Transportation Geotechnics (ICTG 2016), Guimarães, Portugal, Correia, A. G., Editor. Elsevier, Amsterdam, the Netherlands, vol. 143, pp. $435-444$.

Liikennevirasto (2012). Geolujitetut Maarakenteet, Tiegeotekniikan Käsikirja, Liikenneviraston Oppaita 2/2012, Liikennevirasto, Helsinki, Finland (in Finnish).

Ling, J. M., Qian, J. S. \& Huang, Q. L. (2003). New Technologies of Subgrade Widening for Highways. Internal Report. Tongji University, Changsha Science, Technology University (in Chinese).

Liu, K. W. \& Rowe, R. K. (2015). Numerical modelling of prefabricated vertical drains and surcharge on reinforced floating columnsupported embankment behavior. Geotextiles and Geomembranes, 43, No. 6, 493-505.

Liu, H. L., Ng, C. W. W. \& Fei, K. (2007). Performance of a geogrid-reinforced and pile-supported highway embankment over soft clay: case study. Journal of Geotechnical and Geoenvironmental Engineering, 133, No. 12, 1483-1493.

Lodder, H. J., Van Eekelen, S. J. M. \& Bezuijen, A. (2012). The influence of subsoil reaction in a basal reinforced piled embankment. Proceedings of the 5th European Geosynthetics Congress (Eurogeo 5), Valencia, Spain. CRC Press, Boca Raton, FL, USA, vol 5, pp. $390-394$

Low, B. K., Tang, S. K. \& Choa, V. (1994). Arching in piled embankments. Journal of Geotechnical Engineering, 120, No. 11, 1917-1938

Lu, W. \& Miao, L. (2015). A simplified 2-D evaluation method of the arching effect for geosynthetic-reinforced and pile-supported embankments. Computers and Geotechnics, 65, 97-103.

Lu, W., Miao, L., Wang, F., Zhang, J., Zhang, Y. \& Wang, H. (2020). A case study on geogrid-reinforced and pile-supported widened highway embankment. Geosynthetics International, Special Issue on Geosynthetic-Reinforced Pile-Supported Embankments, https://doi.org/10.1680/jgein.19.00024

Marston, A. \& Anderson, A. O. (1913). The Theory of Loads on Pipes in Ditches and Tests of Cement and Clay Drain Tile and Sewer Pipe, Engineering Experiment Station, Bulletin No. 31, Iowa State College of Agriculture and Mechanic Arts, Ames, Iowa, USA, 181p.

McGuire, M. P. (2011). Critical Height and Surface Deformation of Column-Supported Embankments, $\mathrm{PhD}$ thesis, Virginia Tech, Blacksburg, VA, USA.

McGuire, M. P. \& Filz, G. M. (2008). Quantitative comparison of theories for geosynthetic reinforcement of column-supported embankments. The First Pan American Geosynthetics Conference \& Exhibition, 2-5 March 2008, Cancun, Mexico, pp. 1303-1312.

McGuire, M., Sloan, J., Collin, J. \& Filz, G. (2012). Critical height of column-supported embankments from bench-scale and field-scale tests. ISSMGE - TC 211 International Symposium on Ground Improvement IS-GI, 31 May \& 1 June 2012, Brussels, Belgium.

McGuire, M., Sloan, J. \& Filz, G. (2020). Effectiveness of geosynthetic-reinforcement for load transfer in column-supported embankments. Geosynthetics International, GeosyntheticReinforced Pile-Supported Embankments, https://doi.org/10.1680/ jgein.19.00012.

McKelvey, J. A. (1994). The anatomy of soil arching. Geotextiles and Geomembranes, 13, 317-329.

McNulty, J. W. (1965). An Experimental Study of Arching in Sand, Rep. No. I-674. U.S. Army Engineer Waterways Experiment Station, Corps of Engineers, Vicksburg, Mississippi, USA, 170pp.

Naughton, P. (2007). The Significance of Critical Height in the Design of Piled Embankments. Soil Improvement, 1-10, https://doi.org/ $10.1061 / 40916(235) 3$

Navin, M. P. (2005). Stability of Embankments Founded on Soft Soil Improved with Deep-Mixing Method Columns. Ph.D dissertation, Virginia Tech, Blacksburg, VA, USA.
NGG (Nordic Geosynthetic Group) (2004). Nordic Guidelines for Reinforced Soils and Fills, Nordic Geosynthetic Group, Oslo, Norway.

Oh, Y. I. \& Shin, E. C. (2007). Reinforced and arching effect of geogrid-reinforced and pile-supported embankment on marine soft ground. Marine Georesources and Geotechnology, 25, No. 2, 97-118.

Pham, T. A. (2020). Load-deformation of piled embankments considering membrane effect and interface friction. Geosynthetics International, Special Issue on Geosynthetic-Reinforced Pile-Supported Embankments, https://doi.org/10.1680/jgein. 19.00030

Pham, H. V., Dias, D. \& Dudchenko, A. (2020). 3D Modeling of geosynthetic-reinforced pile-supported embankment under cyclic loading. Geosynthetics International, Special Issue on Geosynthetic-Reinforced Pile-Supported Embankments, https:/l doi.org/10.1680/jgein.18.00039.

PWRC (Public Works Research Center) (2000). Manual on Design and Construction of Geosynthetic-Reinforced Earth, Geosynthetic-Reinforced Earth Committee, Japan, Revised version, p. 305.

Rathmayer, H. (1975). Piled embankment supported by single pile caps. Proceedings of Istanbul Conference on Soil Mechanics and Foundation, Istanbul Teknik Üniversitesi, Istanbul, Turkey.

Reid, W. M. \& Buchanan, N. W. (1984). Bridge Approach Support Piling. Piling and Ground Treatment, Thomas Telford Ltd, London, UK.

Reshma, B., Rajagopal, K. \& Viswanadham, B. V. S. (2020). Centrifuge model studies on the settlement response of geogrid reinforced piled embankments. Geosynthetics International, Special Issue on Geosynthetic-Reinforced Pile-Supported Embankments, https:// doi.org/10.1680/jgein.19.00009.

Rogbeck, Y., Gustavsson, S., Södergren, I. \& Lindquist, D. (1998) Reinforced piled embankments in Sweden - design aspects. In Proceedings of the Sixth International Conference on Geosynthetics, pp. 755-762.

Rowe, R. K. \& Liu, K. W. (2015). Three-dimensional finite element modelling of a full-scale geosynthetic-reinforced, pile-supported embankment. Canadian Geotechnical Journal, 52, No. 12 , 2041-2054, https://doi.org/10.1139/cgj-2014-0506.

Rui, R., van Tol, A. F., Xia, Y. Y., Van Eekelen, S. J. M. \& Hu, G. (2016a). Investigation of soil-arching development in dense sand by 2D model tests, Geotechnical Testing Journal, 39, No. 3, 415-430, https://doi.org/10.1520/GTJ20150130. ISSN 0149-6115.

Rui, R., Van Tol, F. A., Xia, X. L., Van Eekelen, S. J. M., Hu, G. \& Xia, Y. Y. (2016b). Evolution of soil arching; 2D DEM simulations. Computers and Geotechnics, 73, 199-209, https://doi.org/10.1016/ j.compgeo.2015.12.006.

Rui, R., Van Tol, F. A., Xia, Y. Y., Van Eekelen, S. J. M. \& Hu, G. (2018). Evolution of soil arching: 2D analytical models. International Journal of Geomechanics, 18, No. 6, 04018056, https://doi.org/ 10.1061/(ASCE)GM.1943-5622.0001169.

Rui, R., Han, J., Van Eekelen, S. J. M. \& Wan, Y. (2019a). Experimental investigation of soil-arching development in unreinforced and geosynthetic-reinforced pile-supported embankments. Journal of Geotechnical and Geoenvironmental Engineering, 145, No. 1, 04018103, doi:e10.1061/(ASCE)GT.1943-5606.0002000.

Rui, R., Han, J., Zhang, L., Zhai, Y., Cheng, Z. \& Chen, C. (2019b). A simplified method to estimate vertical stress-settlement responses of piled embankments on soft soils. Computers and Geotechnics, 73, 199-209, https://doi.org/10.1016/j.compgeo.2015. 12.006.

Rui, R., Zhai, Y., Han, J., Van Eekelen, S. J. M. \& Chen, C. (2020). Deformations in trapdoor tests and piled embankments. Geosynthetics International, Special Issue on GeosyntheticReinforced Pile-Supported Embankments, https://doi.org/10.1680/ jgein.19.00014.

Russell, D. \& Pierpoint, N. (1997). An assessment of design methods for piled embankments. Ground Engineering, 30, No. 10, 39-44. 
Satibi, S. (2009). Numerical Analysis and Design Criteria of Embankments on Floating Piles. $\mathrm{PhD}$ Thesis, Universität Stuttgart, Stuttgart, Germany.

Schaefer, V. R., Berg, R. R., Collin, J. G., Christopher, B. R., DiMaggio, J. A., Filz, G. M., Bruce, D. A. \& Ayala, D. (2017). Ground Improvement Methods - Reference Manual Vols. I and II, FHWA-NHI-16-027 and FHWA-NHI-16-028, Washington, DC, USA

Shen, P., Xu, C. \& Han, J. (2018). Model tests investigating spatial tensile behavior of simulated geosynthetic reinforcement material over rigid supports. ASCE Materials in Civil Engineering, 30, No. 2, 04017288-1-04017288-12

Shen, P., Xu, C. \& Han, J. (2020a). Geosynthetic-reinforced pilesupported embankment: settlement in different pile conditions. Geosynthetics International, Special Issue on GeosyntheticReinforced Pile-Supported Embankments, https://doi.org/10.1680/ gein.19.00015.

Shen, P., Xu, C. \& Han, J. (2020b). Centrifuge tests to investigate global performance of geosynthetic-reinforced pile-supported embankments with side slopes. Technical note, Geotextiles and Geomembranes, 48, No. 1, 120-127.

Sloan, J. A. (2011). Column-supported Embankments: Full-Scale Tests and Design Recommendations. PhD thesis, Virginia Polytechnic Institute and State University, Blacksburg, VA, USA.

Sloan, J. A., McGuire, M. P. \& Gallant, A. P. (2019). Load displacement compatibility method for design of column-supported embankments: comparison to case histories. Eighth International Conference on Case Histories in Geotechnical Engineering, Philadelphia, PA, USA, ASCE, Reston, VA, USA, https://doi. org/10.1061/9780784482162.004.

Smith, M. E. (2005). Design of Bridging Layers in GeosyntheticReinforced Column-Supported Embankments. Ph.D. thesis, Virginia Polytechnic Institute and State Univ., Blacksburg, VA, USA.

Song, J., Chen, K., Li, P., Zhang, Y. \& Sun, C. (2018). Soil arching in unsaturated soil with different water table. Granular Matter, 20, 78, https://doi.org/10.1007/s10035-018-0849-3.

Svanø, G., Ilstad, T., Eiksund, G. \& Want, A. (2000). Alternative calculation principle for design of piled embankments with base reinforcement. Proceedings 4th International Conference on Ground Improvement Geosystems, Finnish Geotechnical Society, Helsinki, Finland.

Terzaghi, K. (1936). Stress distribution in dry and in saturated sand above a yielding trap-door. Proceedings of the International Conference of Soil Mechanics, Harvard University, Cambridge, USA, pp. 307-311.

Terzaghi, K. (1943). Theoretical Soil Mechanics, John Wiley and Sons, New York, NY, USA.

Van der Peet, T. C. \& Van Eekelen, S. J. M. (2014). 3D Numerical analysis of basal reinforced piled embankments. Proceedings of the 10th International Conference on Geosynthetics (10ICG), Deutsche Gesellschaft Für Geotechnik (DGGT), Berlin, Germany, Paper number 112.

Van der Stoel, A., Brok, C. \& de Lange, A. (2012). Piled embankments in the Netherlands: Lelystad-Zwolle (Hanzelijn) and AmstersfoortZwolle rail intersection. Proceedings of the 5th European Geosynthetics Congress (Eurogeo 5), Valencia, Spain, CRC Press, Boca Raton, FL, USA, vol. 5, pp. 537-541.

Van Duijnen, P. G., Van Eekelen, S. J. M. \& Van der Stoel, A. E. C. (2010). Monitoring of a railway piled embankment. Proceedings of the 9th International Conference on Geosynthetics (ICG9), IGS-Brazil, Guarujá, Brazil, pp. 1461-1464.

Van Eekelen, S. J. M. (2015). Basal Reinforced Piled Embankments. $\mathrm{PhD}$ thesis, Delft University of Technology, Delft, the Netherlands. See http://repository.tudelft.nl/view/ir/uuid\%3A492dc4f3-9345$439 \mathrm{e}-9268-7 \mathrm{c} 27 \mathrm{c} 57 \mathrm{e} 110 \mathrm{~b} /$

Van Eekelen, S. J. M. (2016). The 2016-update of the Dutch Design Guideline for Basal Reinforced Piled Embankments. Advances in transportation geotechnics 3. The 3rd International Conference on Transportation Geotechnics (ICTG 2016), Guimarães, Portugal, Correia, A. G., Editor. Elsevier, Amsterdam, the Netherlands, vol. 143, pp. 582-589, https://doi.org/10.1016/ j.proeng.2016.06.077.
Van Eekelen, S. J. M. \& Bezuijen, A. (2008). Design of piled embankments, considering the basic starting points of the British standard BS8006. Proceedings of the 4th European Geosynthetics Congress (EuroGeo 4), IGS, Edinburgh, UK, paper number 315.

Van Eekelen, S. J. M. \& Bezuijen, A. (2013). Dutch research on basal reinforced piled embankments. Proceedings of Geo-Congress, ASCE, San Diego, CA, USA, pp. 1838-1847.

Van Eekelen, S. J. M. \& Bezuijen, A. (2014). Is $1+1=2$ ? Results of 3D model experiments on piled embankments. Proceedings of the 10th International Conference on Geosynthetic (10ICG), Deutsche Gesellschaft Fuer Geotechnik (DGGT), Berlin, Germany, paper number 128.

Van Eekelen, S. J. M. \& Brugman, M. H. A., Editors, (2016). Design Guideline Basal Reinforced Piled Embankments (CUR226), CRC Press, Leiden, the Netherlands.

Van Eekelen, S. J. M. \& Lodder, H. J. (2016). Non-square rectangular pile arrangements and load distribution in basal reinforced piled embankments. Proceedings of the 6th European Geosynthetics Congress (EuroGeo 6), Ljubljana, Slovenia, pp. 1238-1249.

Van Eekelen, S. J. M., Bezuijen, A. \& Oung, O. (2003). Arching in piled embankments; experiments and design calculations. Proceedings of the ICOF Conference, Dundee, Scotland. Thomas Telford, London, UK, pp. 885-894.

Van Eekelen, S. J. M., Van, M. A. \& Bezuijen, A. (2007). The Kyoto Road, a Full-scale Test, Measurements and Calculations. Proceedings of the 14th European Conference on Soil Mechanics and Geotechnical Engineering, Madrid, Spain, pp. 1533-1538.

Van Eekelen, S. J. M., Bezuijen, A. \& Alexiew, D. (2010). The Kyoto road piled embankment: $3 \frac{1}{2}$ years of measurements. Proceedings of the 9th International Conference on Geosynthetics (ICG9), IGS-Brazil, Guarujá, Brazil, pp. 1941-1944.

Van Eekelen, S. J. M., Bezuijen, A. \& Van Tol, A. F. (2011a). Analysis and modification of the British Standard BS8006 for the design of piled embankments. Geotextiles and Geomembranes, 29, No. 3, 345-359.

Van Eekelen, S. J. M., Lodder, H. J. \& Bezuijen, A. (2011b). Load distribution on the geosynthetic reinforcement within a piled embankment. In Proceedings of ICSMGE 2011, Athens, Greece, pp. 1137-1142.

Van Eekelen, S. J. M., Bezuijen, A., Lodder, H. J. \& Van Tol, A. F. (2012a). Model experiments on piled embankments part I. Geotextiles and Geomembranes, 32, 69-81.

Van Eekelen, S. J. M., Bezuijen, A., Lodder, H. J. \& Van Tol, A. F. (2012b). Model experiments on piled embankments. Part II, Geotextiles and Geomembranes, 32, 82-94, including its Corrigendum in Geotextiles and Geomembranes, 35: 119.

Van Eekelen, S. J. M., Bezuijen, A. \& Van Duijnen, P. G. (2012c). Does a piled embankment 'feel' the passage of a heavy truck? High frequency field measurements. Proceedings of the 5th European Geosynthetics Congress (EuroGeo 5), Valencia, Spain. CRC Press, Boca Raton, FL, USA, vol. 5, pp. 162-166.

Van Eekelen, S. J. M., Almeida, M. S. S. \& Bezuijen, A. (2014). European analytical calculations compared with a full-scale Brazilian piled embankment. Proceedings of the 10th International Conference on Geosynthetic (10ICG), Deutsche Gesellschaft Fuer Geotechnik (DGGT), Berlin, Germany, Paper no. 127.

Van Eekelen, S. J. M., Bezuijen, A. \& van Tol, A. F. (2013). An analytical model for arching in piled embankments. Geotextiles and Geomembranes 39, 78-102.

Van Eekelen, S. J. M., Bezuijen, A. \& van Tol, A. F. (2015). Validation of analytical models for the design of basal reinforced piled embankments. Geotextiles and Geomembranes, 43, No. 1, 56-81.

Van Eekelen, S. J. M., Venmans, A. A. M., Bezuijen, A. \& Van Tol, A. F. (2020). Long term measurements in the Woerden geosynthetic-reinforced pile-supported embankment. Geosynthetics International, Special Issue on Geosynthetic-Reinforced Pile-Supported Embankments, https://doi.org/10.1680/jgein.17. 00022.

Völlmy, A. (1937). Eingebettete Rohre, Mitt, Mitt. no. 9. Inst. Baustatik, Eidgen. Tech. Hochschule, Zürich, Switzerland. 
Wachman, G. S., Biolzi, L. \& Labus, J. F. (2010). Structural behaviour of a pile-supported embankment. Journal of Geotechnical and Geoenvironmental Engineering, 36, No. 1, 26-34.

Wijerathna, M. \& Liyanapathirana, D. S. (2020). Load transfer mechanism in geosynthetic reinforced column-supported embankments, Geosynthetics International, Special Issue on Geosynthetic-Reinforced Pile-Supported Embankments, https://doi. org/10.1680/jgein.19.00022.

Wu, J., Liao, S. M. \& Liu, M. B. (2019). An analytical solution for the arching effect induced by ground loss of tunneling in sand. Tunnelling and Underground Space Technology, 83, 175-186.

Xing, H., Zhang, Z., Liu, H. \& Wei, H. (2014). Large-scale tests of pile-supported earth platform with and without geogrid. Geotextiles and Geomembranes, 42, No. 6, 586-598.

Xu, C., Song, S. \& Han, J. (2016). Scaled model tests on influence factors of full geosynthetic-reinforced pile-supported embankments. Geosynthetics International, 23, No. 2, 140-153.

Xu, C., Zhang, X. Y., Han, J. \& Yang, Y. (2019). Two-dimensional soil-arching behavior under static and cyclic loading. ASCE International Journal of Geomechanics, 19, No. 8, 04019091-1-14.

Yapage, N. N. S. \& Liyanapathirana, D. S. (2014). A parametric study of geosynthetic-reinforced column-supported embankments. Geosynthetics International, 21, No. 3, 213-232.

Yapage, N. N. S., Liyanapathirana, D. S., Leo, C. J. Poulos, H. G. \& Kelly, R. B. (2012). An investigation of arching mechanism of geosynthetic reinforced column supported embankments. In Proceedings of the Australasian Conference on the Mechanics of Structures and Materials. From Materials to Structures: Advancement Through Innovation: Proceedings of the 22nd Australian Conference on the Mechanics of Structures and Materials, University of Technology, 11-14 December 2012, Sydney, Australia. CRC Press.

Yu, Y., Bathurst, R. J. \& Damians, I. P. (2016). Modified unit cell approach for modelling geosynthetic-reinforced column-supported embankments. Geotextiles and Geomembranes, 44, No. 3, 332-343.
Zaeske, D. (2001). Zur Wirkungsweise von Unbewehrten und Bewehrten Mineralischen Tragschichten über Pfahlartigen Gründungselementen. $\mathrm{PhD}$ Thesis, Schriftenreihe Geotechnik, Universität Gh Kassel, Kassel, Germany. Heft 10 (in German).

Zhang, L., Zhao, M., Hu, Y., Zhao, H. \& Chen, B. (2012). Semianalytical solutions for geosynthetic-reinforced and pile-supported embankment, Computers and Geotechnics, 44, No. 2012, 167-175, https://doi.org/10.1016/j.compgeo.2012.04. 001, ISSN 0266-352X

Zhang, C., Jiang, G., Liu, X. \& Buzzi, O. (2016). Arching in geogrid-reinforced pile-supported embankments over silty clay of medium compressibility: field data and analytical solution. Computers and Geotechnics, 77, 11-25.

Zhang, Z., Wang, M., Ye, G. B. \& Han, J. (2017). Influence of number of geosynthetic layers on the performance of geosynthetic-reinforced pile-supported earth platforms on soft soil: numerical study. Proceedings of the 2017 International Conference on Transportation Infrastructure and Materials (ICTIM 2017), Qingdao, China, DEStech Publications, Lancaster, PA, USA.

Zhang, Z., Wang, M., Ye, G. B. \& Han, J. (2019). A novel 2D-3D conversion method for calculating maximum strain of geosynthetic reinforcement in pile-supported embankments. Geotextiles and Geomembranes, 47, No. 3, 336-351.

Zheng, J. J., Chen, B. G., Lu, Y. E., Abusharar, S. W. \& Yin, J. H. (2009). The performance of an embankment on soft ground reinforced with geosynthetics and pile walls. Geosynthetics International, 16, No. 3, 173-182.

Zheng, G., Yang, X., Zhou, H. \& Chai, J. (2019). Numerical modeling of progressive failure of rigid piles under embankment load. Canadian Geotechnical Journal, 56, No. 1, 23-34.

Zhuang, Y., Chen, X. \& Wang, K. (2020). Analytical solution for geogrid-reinforced piled embankments under traffic loads. Geosynthetics International, Special Issue on GeosyntheticReinforced Pile-Supported Embankments, https://doi.org/10.1680/ jgein.19.00023.

The Editor welcomes discussion on all papers published in Geosynthetics International. Please email your contribution to discussion@geosynthetics-international.com by 15 October 2020. 